\title{
The Syntax and Prosody of Weak Pronouns in Chamorro
}

\author{
Sandra Chung
}

In the modular linguistic theory assumed by many generative linguists, phonology and syntax are interconnected but fundamentally independent components of grammar. The effects of syntax on phonology are mediated by prosodic structure, a representation of prosodic constituents calculated from syntactic structure but not isomorphic to it. Within this overall architecture, I investigate the placement of weak pronouns in the Austronesian language Chamorro. Certain Chamorro pronominals can be realized as prosodically deficient weak pronouns that typically occur right after the predicate. I show that these pronouns are second-position clitics whose placement is determined not syntactically, but prosodically: they occur after the leftmost phonological phrase of their intonational phrase. My analysis of these clitics assumes that lexical insertion is late and can affect and be affected by prosodic phrase formation-assumptions consistent with the view that the mutual interaction of phonology and syntax is confined to the postsyntactic operations that translate syntactic structure into prosodic structure.

Keywords: clitics, second position, phonological phrase, prosodic hierarchy, lexical insertion, modularity

\section{The Point of Departure}

Research on the syntax-phonology interface has been remarkably successful at articulating the senses in which phonology and syntax, though interconnected, are fundamentally independent. On the phonological side, the work of Nespor and Vogel $(1982,1986)$, Selkirk $(1980,1986)$ and her associates (e.g., Hale and Selkirk 1987, Selkirk and Tateishi 1991), Hayes (1989, 1990), Truckenbrodt $(1995,1999)$, and others has established that phonological rules do not have direct access to syntactic information (for an opposing view, see Kaisse 1985). Instead, the effects of syntax on phonology are mediated by prosodic structure, a hierarchical representation of prosodic

Heartfelt thanks to Manuel F. Borja, Maria P. Mafnas, Maria T. Quinata, Anicia Q. Tomokane, Francisco Tomokane, and the many other Chamorro speakers who contributed to this study. I also wish to acknowledge John S. DelRosario, Jr., whose excellent Chamorro-language editorials in the Saipan Tribune during 1998-2001 were the source of many of the examples cited. I am indebted to Judith Aissen, Bruce Hayes, Sharon Inkelas, James McCloskey, and Hubert Truckenbrodt for detailed, constructive comments, and to Anicia Q. Tomokane for her help with the free translations. Portions of this material were presented at the 2001 Texas Linguistic Society Conference (University of Texas, Austin); at the 8th meeting of the Austronesian Formal Linguistics Association (MIT); and at colloquia at the University of California, Berkeley, and the University of California, Santa Cruz. The research reported here was supported in part by funds from the Academic Senate and the Institute for Humanities Research at the University of California, Santa Cruz. 
constituents that is calculated from syntactic structure but not isomorphic to it. On the syntactic side, Pullum and Zwicky (1988) have argued persuasively that syntactic operations do not have direct access to phonological information. Their contention that syntax is "phonology-free" has been almost universally accepted (but see Zec and Inkelas 1990 for an important exception).

These results set the stage for Selkirk's (1986:373) hypothesis that "the level at which prosodic structure forms part of the representation is one where there is no syntactic structure (any more). In other words, once the translation of syntax into prosodic structure is made, the syntax itself falls out of the picture." Such a hypothesis derives the conclusion that syntax and phonology have access to different information from the different vocabularies of their respective levels of representation, plus the modular architecture of grammar. ${ }^{1}$

The overall picture is consistent with approaches to morphology in which the effects of syntax on phonology are mediated in a further way. In theories such as A-morphous Morphology (Anderson 1982, 1992), Distributed Morphology (Marantz 1988, 1989, Halle and Marantz 1993, Embick and Noyer 2001), and Precompiled Phrasal Phonology (Hayes 1990), the terminal nodes of syntactic structure are bundles of morphosyntactic features that are not phonologically instantiated. After this structure exits from the syntax, it undergoes late lexical insertion as well as other "interpretive", operations that, in essence, are responsible for realizing the lexical items in the appropriate linear order, with the appropriate inflectional morphology. The result is an "interpreted" representation derived from, but not identical to, the structure produced by the syntax proper.

The observation raises a question. What, exactly, is the relation between this postsyntactic "interpreted" representation and prosodic structure? It is generally assumed that the operations that build prosodic structure can access the syntactic and lexical information that the "interpreted" representation supplies. But do the postsyntactic operations that create the "interpreted" representation have direct access to prosodic information?

Here I examine some evidence from Chamorro, an Austronesian language of the Mariana Islands, which answers this question in the affirmative. Chamorro has a set of prosodically deficient weak pronouns that typically occur right after the predicate. I analyze these forms as secondposition (2P) clitics whose placement is determined prosodically: they are realized after the leftmost phonological phrase of their intonational phrase (where by "their intonational phrase" I mean the one corresponding most closely to the clause in which they are represented syntactically). The analysis requires late lexical insertion, or whatever postsyntactic operation realizes these forms, to be able to access higher levels of prosodic structure.

The idea that lexical insertion can "see" prosodic constituency is not new. It is explored in depth by Inkelas (1990) and Zec and Inkelas (1990), who propose a model of the syntaxphonology interface in which syntactic structure and prosodic structure are copresent and mutually interacting. In their model, the lexical entries of clitics include a prosodic subcategorization that

\footnotetext{
${ }^{1}$ This is so whether constituents such as the foot, the syllable, and the mora are assumed to form part of the prosodic hierarchy or are located in a separate metrical hierarchy (see Selkirk 1986, Inkelas 1990).
} 
stipulates what type of prosodic constituent the clitic attaches to (on the lexical entries of clitics, see also Klavans 1985). The present article can be viewed as documenting an instance of an underrepresented type of prosodic subcategorization, one that characterizes the notion "second position' in purely prosodic terms. (For other instances, some of which have been controversial, see Radanović-Kocić 1988, 1996, Hock 1996, Taylor 1996, and Bošković 2001.) The analysis leads me to advocate a view of the syntax-phonology interface in which the mutual interaction between syntax and phonology is confined to the postsyntactic operations that translate syntax into prosodic structure: late lexical insertion and morphological operations, on the one hand, and prosodic phrase formation, on the other (see Hayes 1990:108).

Most accounts of the placement of $2 \mathrm{P}$ clitics take it for granted that "second position" is characterized partly or exclusively in syntactic terms (see, e.g., Marantz 1988, 1989, Sadock 1991, Anderson 1992, 1993, 2000, Black 1992, Rivero 1994, Halpern 1995, Legendre 1996, Progovac 1996, Bošković 2001, Condoravdi and Kiparsky 2002). The first half of this article is devoted to showing that the "second position" relevant to Chamorro weak pronouns is not amenable to such a characterization. Section 2 introduces the weak pronouns. Section 3 constructs a representative "straw" analysis that would treat these forms as (the content of) syntactic heads preceded by exactly one maximal projection within their clausal domain. Section 4 presents some distributional evidence that such a "straw" analysis could not handle, either on its own or augmented by a repair strategy such as prosodic inversion (see Halpern 1995). Section 5 argues that the "second position" relevant to weak pronouns can be characterized in purely prosodic terms. Section 6 explores some predictions made by this prosodic account. Finally, section 7 discusses the mechanisms responsible for the placement of these forms.

\section{Introducing Weak Pronouns}

Chamorro is a head-initial language in which predicates can be of any major category type. In pragmatically neutral clauses, the predicate precedes its arguments. The word order of clauses containing verbs is otherwise rather flexible, although the most frequent surface order is VSO (see Chung 1998). Consider the following examples ( $L=$ linker, $A P=$ antipassive):

(1) a. Yanggin tiempu-n kamuti, pues siempri mañ-akki i dos kamuti. if time-L sweet.potato then surely AGR.AP-steal the two sweet.potato 'When it was sweet potato season, then the two would steal sweet potatoes.'

b. Maolik ennao na intensión yänggin magahit na primera responsabilidát AGR.good that $\mathrm{L}$ intention if AGR.true COMP first responsibility gubietnu i pära u-fam-a'ganansia.

government the FUT AGR-AP-make.profit

'That idea is good if, in fact, making a profit is the government's primary responsibility.' (Saipan Tribune 6/22/00)

c. Siempri u-ganna i White House si Governor Bush.

surely AGR-win the White House Governor Bush

'Governor Bush will surely win the White House.' (Saipan Tribune 1/18/00) 
In addition to null pronouns, which occur in a variety of syntactic contexts, Chamorro has two paradigms of overt pronouns that are essentially in complementary distribution. Weak pronouns are used to represent pronominal subjects and direct objects. Independent pronouns are used to represent other pronominals: obliques, objects of prepositions, and pronominals that are conjoined or occur in topic or focus position.

(2) Overt pronouns in Chamorro

$\begin{array}{lll} & \text { Weak } & \text { Independent } \\ 1 \mathrm{sg.} & \text { yu' } & \text { guahu } \\ 2 \mathrm{sg} . & \text { hao } & \text { hagu } \\ 3 \text { sg. anim. } & \text { gui' } & \text { guiya } \\ 1 \text { incl. pl. } & \text { hit } & \text { hita } \\ 1 \text { excl. pl. } & \text { häm } & \text { hämi } \\ 2 \text { pl. } & \text { hämyu } & \text { hämyu } \\ 3 \text { pl. anim. } & \text { siha } & \text { siha }\end{array}$

Whereas independent pronouns have the inflectional profile and positional freedom of full DPs, weak pronouns are special clitics in Zwicky's (1977) sense. It is the weak pronouns that are the focus of interest here.

What are the reasons for classifying weak pronouns as special clitics? To begin with, they are prosodically deficient enclitics: unstressed forms, mostly monosyllables, that must form a prosodic constituent with host material to their left. Like typical clitics but unlike affixes, they "exhibit a low degree of selection with respect to their hosts" (Zwicky and Pullum 1983:503). Consider the following examples, in which the weak pronouns are italicized:

(3) a. Um-ä-kumprendi hit. AGR-RECIP-understand we

'We agree (lit. understand each other).'

b. Esta ti parehu hit. already not AGR.same we 'We aren't the same anymore.'

c. Pära i tenda hit guätu gi una ora. to the store we over.there LOC an hour 'We're going to the store in an hour.'

They can also "attach to material already containing clitics" (Zwicky and Pullum 1983:504), such as the polite enclitic fan (4a) and the emphatic enclitic ha' (4b).

(4) a. Sangani fan $y u$ ' hafa huegu-nñiha. say.to please me what? game-AGR 'Please tell me what their games are.' (Sinko na Famagu'on 19)

b. Todu i tiempu ma'a'ñao ha' hao na ti un-nähung gi néngkanu'. all the time AGR.afraid EMP you that not AGR-satisfied LOC food 'You're always afraid you won't get enough to eat.' 
In fact, weak pronouns are evidently unordered with respect to other enclitics. ${ }^{2}$ Compare (4) with (5).

(5) a. Fahani $y u$ ' fan gä'-hu ga'lagu.

buy.for me please pet-AGR dog

'Please buy me a pet dog.' (Cooreman 1983:108)

b. Kao hinähassu hao ha' ni ma'estro-mmu?

Q AGR.PASS.remember.PROG you EMP OBL teacher-AGR

'Does your teacher still remember you?'

Consistent with their prosodic deficiency, weak pronouns cannot appear in positions of syntactic focus.

(6) a. In-disfruta siha, ti hagu/*hao.

AGR-criticize them not you

'We criticized them, not you.'

b. Guahu/*Yu' si Fanihi.

I Fanihi

'I am Fruit-bat.' (Hayi Hao? 8)

Nor can they be inflected for morphological case (7a) or appear immediately after prepositions or conjunctions (7b).

(7) a. Ma'a'ñao i gä'-hu ga'lagu nu hagu/*hao.

AGR.afraid the pet-AGR dog OBL you

'My dog is afraid of you.'

b. Ti um-ä-kumprendi hao yan guahu/*yu'.

not AGR-RECIP-understand you and I

'You and I don't understand each other.'

This last point has a prosodic explanation: case particles, prepositions, and conjunctions in Chamorro are proclitics — they must form a prosodic constituent with host material to their right — but weak pronouns are enclitics. When the two types of elements are arranged in the order procliticenclitic, as in (7), no well-formed prosodic structure can meet the demands of both.

Weak pronouns have a positional distribution significantly different from that of the corresponding full DPs. They do not have the word order freedom of nonpronominal subjects and direct objects. ${ }^{3}$

\footnotetext{
${ }^{2}$ In (5b), the emphatic enclitic ha' modifies the verb, not the weak pronoun: it combines with the verb's progressive aspect to give a continuative meaning translated here as 'still'.

The question of how weak pronouns are ordered with respect to one another does not arise, because clitic clusters in Chamorro never contain more than one weak pronoun.

${ }^{3}$ The claim that nonpronominal subjects or direct objects can occur in positions where weak pronouns cannot is massively supported by evidence from written materials, naturally occurring discourse (including narratives), and sentences volunteered in elicitation. Nonetheless, when presented with isolated Chamorro examples in which a weak pronoun has
} 
(8) a. ??Ha-istótotba i buruka $y u$ '.

AGR-disturb.PROG the noise me

'The noise is disturbing me.'

b. Ha-pänak i petta $i$ patas-su.

AGR-bang the door the foot-AGR

'The door banged my foot.'

On the other hand, they can surface in positions where nonpronominal subjects and direct objects would not occur.

(9) a. Kao patgon-ña hao ädyu na ma'estra?

Q child-AGR you that $\mathrm{L}$ teacher

'Are you the child of that teacher?'

b. *Kao patgon-ña si Dolores ädyu na ma'estra?

Q child-AGR Dolores that $\mathrm{L}$ teacher

('Is Dolores the child of that teacher?')

These differences identify them as special clitics. The claim that they are $2 \mathrm{P}$ clitics in particular is substantiated by evidence to be presented below.

Observe finally that Chamorro requires pronominals that are cross-referenced by agreement in person to be phonologically null: they cannot be realized as overt pronouns, whether weak or independent (Chung 1998:29-32). The DPs cross-referenced by agreement in person include the subjects of transitive verbs (10a), the subjects of irrealis verbs and adjectives (10b), and certain possessors (10c).

(10) a. Hu-fahan (*yu') i lepblu.

AGR-buy I the book

'I bought the book.'

b. Pära bai infan-mattu (*häm) agupa'.

FUT AGR-arrive us tomorrow

'We will arrive tomorrow.'

c. Puti (*yu') ilu-hu.

AGR.hurt I head-AGR

'My head hurts.'

Because pronominals that serve these functions are never overt, weak pronouns are in effect limited to representing direct objects and certain intransitive subjects. For this reason, I and others

\footnotetext{
been placed in a "nonpronominal" position, speakers are interestingly reluctant to judge the result to be completely ungrammatical. I do not know why this is so. A contributing factor may be the limitations on my ability to reproduce Chamorro intonation patterns, which are characterized by the same reverse stress-pitch correlation found in Chamorro words. For another report of variable judgments on the placement of 2P clitics, see Radanović-Kocić (1988) on SerboCroatian.
} 
have sometimes referred to them as absolutive pronouns. The fact that weak pronouns cannot be used to represent transitive subjects goes some way toward explaining why clitic clusters in Chamorro never contain more than one weak pronoun.

\section{A Purely Syntactic Approach}

From a syntactician's perspective, the most congenial approach to $2 \mathrm{P}$ clitics is one that accomplishes the placement of these forms entirely within the syntax, via familiar operations that build phrase structure and/or perform movement. Here I construct a garden-variety analysis of this type, which I will argue in section 4 is made of straw. Section 3.1 sketches the analysis. Section 3.2 discusses a theoretical consideration that might lead one to want to pursue it further. Finally, section 3.3 presents an initial empirical difficulty.

\subsection{Weak Pronouns as Clausal Heads}

Most purely syntactic analyses of $2 \mathrm{P}$ clitics treat them as the content of syntactic heads that raise to C, T, Agr, or some other functional head located fairly high within the clause (see, e.g., Black 1992, Haverkort 1993, Rivero 1994, Progovac 1996). Such an approach claims that 2P clitics have essentially the same syntax as finite verbs in a verb-second language: they surface in a higher functional head, preceded by exactly one maximal projection, which can be identified as that head's specifier. ${ }^{4}$ On this view, the only sense in which $2 \mathrm{P}$ clitics are "special" is prosodic: unlike prototypical verbs, they happen to be prosodically deficient.

Pursuing this style of analysis, suppose we were to claim that Chamorro weak pronouns were Ds that raise to some designated clausal head. Two questions would immediately arise. What is the designated clausal head, and what material can occupy its specifier?

In response to the first question, notice that when weak pronouns appear in embedded clauses, they are positioned not in the vicinity of the complementizer but farther to the right-typically, after the embedded predicate (bracketed in the examples below).

(11) a. Man-maleffa na [mansiudadanu-n Amerikanu] hit lokkui'. AGR-forget COMP citizens-L American we also 'They've forgotten that we are also American citizens.' (Saipan Tribune 8/17/99)

b. Maolek-ña yänggin [sumaga] $y u^{\prime}$ manu nai [gaigi] $y u^{\prime}$ pa'gu. AGR.good-COMPAR if AGR.stay I where? COMP AGR.be I now 'It's better if I continue doing what I'm doing now.' (Saipan Tribune 1/16/01)

This suggests that they do not raise all the way to $\mathrm{C}$ but instead raise to some nearer clausal head, such as T or Agr. ${ }^{5}$

\footnotetext{
${ }^{4}$ The connection between 2P clitics and verb-second is discussed from a different perspective by Anderson (1993).

${ }^{5}$ Further issues would have to be settled before one could decide whether the destination was T or Agr. I will not investigate these issues here, since I plan to reject the analysis later.
} 
As to the second question, inspection suggests that the category occupying the specifier of this clausal head is simply the predicate XP. A weak pronoun can be preceded by an entire DP predicate, for instance.

(12) a. [Águaguat na patgun] gui'. naughty $\mathrm{L}$ child he 'He's a naughty child.'

b. [Más yä-hu na taotao] hao. most wH[OBJ].like-AGR L person you 'You're the person I like most.'

c. [Man-suetti-n taotao] hit. AGR-lucky-L people we 'We are such lucky people.' (Saipan Tribune 12/21/00)

It can also be preceded by an entire PP predicate.

(13) a. [Pära manu] yu' pa'gu?

to where? I now

'Where do I [go] now?' (Cooreman 1983:82)

b. [Ginin San Roque na songsung] yu'.

from San Roque L village I

'I'm from San Roque village.'

c. Hu-faisin kao [ginin i guälu' ha'] gui' magi.

AGR-ask Q from the farm EMP he to.here

'I asked [him] if he had just [come] from the farm.' (Saipan Tribune 2/17/00)

These patterns are completely consistent with the idea that the weak pronoun has raised to some clausal head-say, T-and the predicate XP has raised to T's specifier.

\subsection{An Analysis of Clausal Word Order}

Why might predicate XPs in this language raise to the specifier of T? One possible answer emerges from a strand of research, inspired by Kayne (1994), according to which all languages share a core clause structure that is SVO. Clauses with other surface word orders are derived from this minimal SVO structure via leftward movement. For instance, in the work of Pearson (1998), Rackowski and Travis (2000), Aldridge (2002), and others, VOS clauses are derived from the minimal SVO structure by raising VP — more generally, the predicate XP — to the highest specifier of the clause. In the work of Lee (2000) and Massam (2000, 2001), VSO clauses are derived similarly, via raising of a remnant VP. It has been proposed (e.g., by Massam and by Davies and Dubinsky (2001)) that these movements are driven by a version of the Extended Projection Principle (EPP) that targets some feature characteristic of predicates.

For reasons discussed elsewhere (see Chung 1998, to appear), I do not believe that Chamorro clauses can be given an analysis of this sort. Nonetheless, the treatment of V-initial syntax is controversial enough that it seems worth exploring the possibility further. Here is why. Suppose one wished to maintain that verb-initial clauses in all languages were always derived by leftward 
movement of VP, and one could show further that if Chamorro had such a clause structure, the placement of weak pronouns could be described in purely syntactic terms. Then the evidence could be viewed as supporting both claims. More generally, it would provide fuel for a larger research program that aims to derive all surface word order from one core clause structure via movement.

Let us therefore provisionally assume that verb-initial clauses in Chamorro are derived by leftward movement of VP. Then the purely syntactic approach to the placement of weak pronouns, illustrated in (14) for (3a), would build on the claim that the predicate XP raises to T's specifier in every clause, quite independently of whether a weak pronoun happens to be present.

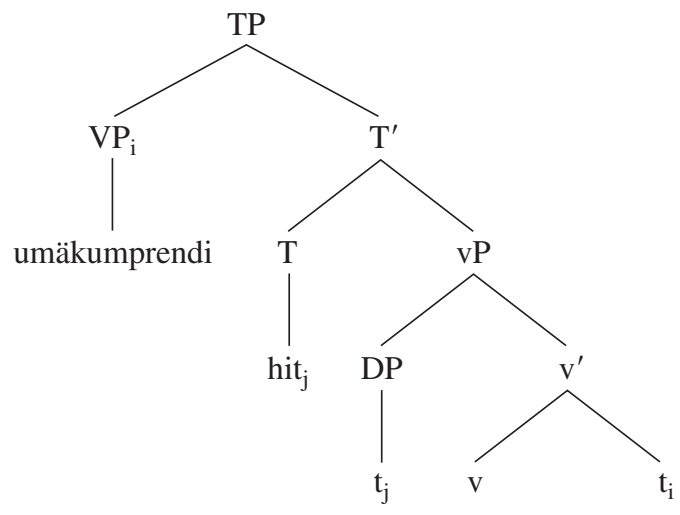

A clause like (1c), for instance, would be derived as shown in (15).

(15)

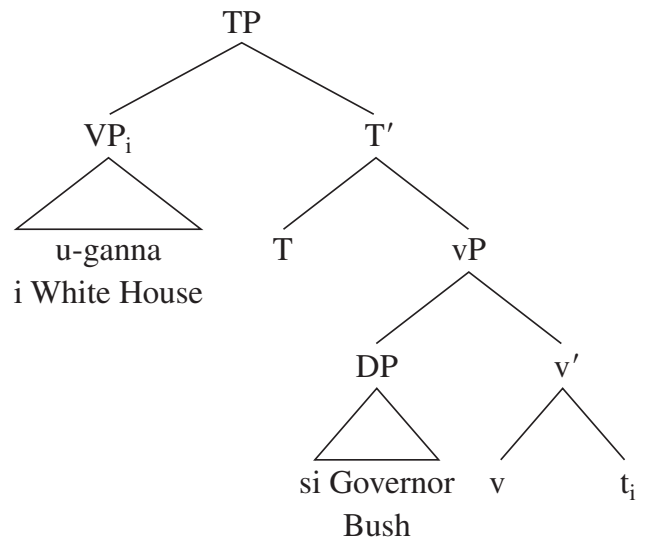

\subsection{An Initial Difficulty}

A difficulty now arises. The purely syntactic approach leads to the expectation that weak pronouns should invariably surface to the right of the predicate XP, whatever its category type. In fact, no positive evidence from VPs or APs bears out this expectation. A weak pronoun can surface immediately after $\mathrm{V}$ or $\mathrm{A}$, as (16)-(17) show. 
(16) a. Malägu' gui' nuebu na kareta. AGR.want she new L car

'She wants a new car.'

b. Kao man-gaigi hit esta gi fondu?

Q AGR-be we already LOC bottom

'Are we at the bottom yet?' (Saipan Tribune 2/15/01)

c. Sigi $y u$ ' luchan pära Koblerville.

AGR.continue I left.when.facing.ocean to Koblerville

'I continued going south to Koblerville.' (Saipan Tribune 3/1/01)

(17) a. Ma'a'ñao $y u^{\prime}$ cha'ka.

AGR.afraid I rat

'I'm afraid of rats.'

b. Ti interesáo hao ni chi'cho'-mu.

not AGR.interested you OBL work-AGR

'You're not interested in your work.'

c. Metgot-ña hao ki guahu.

AGR.strong-COMPAR you than me

'You are stronger than me.' (Cooreman 1982:34)

But weak pronouns never surface after a predicate XP that is unambiguously VP or AP - that consists of $\mathrm{V}$ or A plus its complements and/or adjuncts. Examples of this type are never found in naturally occurring discourse, and they are judged by speakers to be deviant or ill formed (see footnote 3 ).

(18) a. ??[Malägu' nuebu na kareta] gui’.

AGR.want new L car she

('She wants a new car.')

b. ??[Ma'a'ñao nu hagu] $y u$ '.

AGR.afraid OBL you I

('I'm afraid of you.')
c. *[Metgot-ña ki guahu hao.
AGR.strong-COMPAR than me you
('You are stronger than me.')

Following Massam (2000, 2001) and Rackowski and Travis (2000), one could think of conjecturing that in Chamorro, dependents of V or A must raise out of VP or AP for some theoretically motivated reason - for instance, to check Case, or to be interpreted as specific (see Diesing 1992). If so, the constituent immediately preceding the weak pronoun in (16)-(17) could be analyzed as a remnant VP or AP, and the threat to the purely syntactic approach would be removed. But such a conjecture cannot be correct. Most obviously, dependents of V or A would have to exit from VP or AP even if they were PPs and did not need Case (18c), or if they were nonspecific (18a). Further, this forced exit from VP or AP would have to occur exactly when a weak pronoun 
was present-a most suspicious coincidence. Compare (18) with (19), in which there are no weak pronouns and the subject can surface to the right of a complete VP or AP.

(19) a. [Malägu' nuebu na kareta] i lahi-nmami.

AGR.want new L car the son-AGR

'Our son wants a new car.'

b. Ti malate'-ña ki mañe'lu-ña si Pedro.

not AGR.smart-COMPAR than siblings-AGR Pedro

'Pedro is not as smart as his brothers.'

In short, the inability of weak pronouns to be positioned as shown in (18) is problematic for the purely syntactic approach.

This is not the only difficulty that such an approach faces. I now show that there are other aspects of the distribution of these forms that cannot be handled by the purely syntactic approach, either on its own or when augmented by a repair strategy such as prosodic inversion.

\section{Evidence against a Syntactic Approach}

More detailed investigation of the placement of weak pronouns reveals two sorts of surprises, which are discussed in sections 4.1 and 4.2. Section 4.3 explores some further ramifications of the evidence.

\subsection{DP Predicates}

Despite the fact that a weak pronoun can occur to the right of a DP predicate, as was shown in section 3.1, this positioning is not always well formed. There are circumstances under which a weak pronoun cannot follow the entire DP, but must instead surface farther to the left, immediately after N.

For instance, when the DP predicate contains a possessor-which is invariably postnominal-it is impossible for a weak pronoun to follow the entire DP. ${ }^{6}$ Consider (20), in which the DP predicate occurs in brackets.

(20) a. *[Ma'estro-nña si Carmen] gui'. teacher-AGR Carmen he

('He is Carmen's teacher.')

b. ?*Kao [patgon-ña ädyu na ma'estra] hao?

Q child-AGR that $\mathrm{L}$ teacher you

('Are you that teacher's child?')

c. ??[Famagu'on-ña si Tun Kiku'] hit.

children-AGR Tun Kiku' we

('We're Tun Kiku's children.')

\footnotetext{
${ }^{6}$ The discussion in this part of the text is restricted to possessors that trigger person-number agreement on N. For a treatment of possessors linked to $\mathrm{N}$ via the linker, see section 6.2.2.
} 
The weak pronoun must instead occur immediately after $\mathrm{N}$, to the left of the possessor.

(21) a. Ma'estro-nña gui' si Carmen.

teacher-AGR he Carmen

'He is Carmen's teacher.'

b. Kao patgon-ña hao ädyu na ma'estra?

Q child-AGR you that $\mathrm{L}$ teacher

'Are you that teacher's child?'

c. Famagu'on-ña hit si Tun Kiku'.

children-AGR we Tun Kiku'

'We're Tun Kiku's children.'

Similarly, when the DP predicate contains a postnominal modifier such as a PP (22a) or NP (22b), the weak pronoun occurs immediately after $\mathrm{N}$, to the left of the modifier.

(22) a. Famalao'an hit ginin todus i islas gi Pasifika. women we from all the islands LOC Pacific

'We are women from all the islands of the Pacific.'

b. Mañe'lu-ña hit famalao'an si Antonio.

siblings-AGR we women Antonio

'We are Antonio's sisters.'

There is ample evidence that the portion of the DP predicate preceding the weak pronoun in (21)-(22) does not form a freestanding syntactic constituent independent from the possessor or modifier. To begin with, the material preceding the weak pronoun cannot be a remnant DP-a DP from which the possessor or modifier was previously extracted. This is because Chamorro is known not to permit any extraction out of DP predicates. Possessors cannot raise out of these predicates, as the failed instances of wh-movement in (23) are intended to suggest (see Chung 1998:298-299). Notice that these examples are ungrammatical whatever the location of the weak pronoun.

(23) a. *Hayi [kime'-ña t] hit? who? buddy-AGR we

('Whose pals are we?')

b. *Hayi gui' [asagua-ña t]?

who? he spouse-AGR

('Whose spouse is he?')

PP modifiers cannot raise out of DP at all, even a DP that happens to be an argument rather than a predicate. (24a) illustrates that a PP modifier cannot be extracted out of an argument by whmovement (Chung 1998:330-331). (24b) illustrates that a PP modifier cannot be "extraposed" out of a DP predicate, however "'extraposition" is analyzed.

(24) a. *[Ginin mänu $]_{i}$ na guäha [guihan $\left.\mathrm{t}_{\mathrm{i}}\right]_{\text {gi lamäsa? }}$ from where? COMP AGR.exist fish LOC table

('Where were there fish from on the table?') 


\section{b. *[Lepblu $t_{i}$ ] i lepblu-n Susa [put i chiba $]_{i}$. book the book-L Susa about the goat ('Susa's book is a book about goats.')}

Notice further that if the material preceding the weak pronoun were a freestanding syntactic constituent, one would expect a full DP subject to be able to appear immediately to its right. But this is not possible, as is shown by (9b) and (25). (In (25), the full DP subject is enclosed in brackets.)

(25) *Kao i ga'chóchong-ña [ädyu na taotao] si Dolores gi bisnis? Q the partner-AGR.PROG that $\mathrm{L}$ person Dolores LOC business ('Is that person Dolores's partner in business?')

The conclusion seems inescapable that the portions of the DP predicate surrounding the weak pronoun in (21)-(22) are not syntactically independent, but instead form one unified syntactic constituent-presumably, DP. The placement of the weak pronoun in the interior of this DP cannot be accounted for by the purely syntactic approach.

\subsection{Word Order Flexibility}

There is another wrinkle in the placement of weak pronouns that is both typical of special clitics and important here. Under some circumstances, a weak pronoun need not occur after the lexical head of the predicate, but is free to surface farther to the left-an option unavailable, or significantly less available, to the corresponding full DPs. This word order flexibility arises in two sorts of situations.

First, when the lexical head of the predicate is preceded by a modifier, the weak pronoun can either follow the predicate or occur immediately after the modifier. Thus, when a DP predicate contains a prenominal modifier such as an adjective phrase or relative clause, the weak pronoun can surface after $\mathrm{N}$, as was shown in sections 3.1 and 4.1. But it can also occur right after the adjective phrase or relative clause. Compare (12) with (26). In (26a) and (26c), the weak pronoun surfaces right after an adjective phrase. In (26b), it surfaces right after the relative clause CP más yä-hu 'who I like most'.

(26) a. Bunitu gui' na lahi pa'gu.

handsome he L man now

'He was a good-looking man now.' (Saipan Tribune 8/12/99)

b. Más yä-hu hao na taotao.

most $\mathrm{WH}[\mathrm{OBJ}]$. like-AGR you L person

'You're the person I like most.'

c. I más amku' gui' na chi'lu-hu palao'an.

the most old she L sibling-AGR female

'She's my oldest sister.'

The same holds true when the complement of a PP predicate contains a prenominal modifier. Compare (13b) with (27). 
(27) Ginin San Roque yu’ na songsung.

from San Roque I L village

'I'm from San Roque village.'

(Huddleston and Pullum (2001:447) refer to similar modifiers in English as integrated appositives.)

Likewise, when the lexical head of the predicate is preceded by one of the few Chamorro adverbs that must be left-adjoined to the predicate XP (see Chung 1998:130-131), a weak pronoun can occur immediately after the lexical head or immediately after the adverb. In (28), the weak pronoun follows the lexical head, which happens to be V.

(28) a. Käna ha' mámatai yu’ ma’hu.

almost EMP AGR.die.PROG I thirst

'I was almost dying of thirst.' (Saipan Tribune 7/1/99)

b. Duru dinisfruta gui' as Fulanu.

a.lot AGR.PASs.criticize he by So-and-so

'So-and-so had said a lot of bad things about him.' (Saipan Tribune 8/31/99)

c. Kulan man-ma-fuñut hit.

kind.of AGR-PASs-wring.out we

'We were kind of wrung out.' (Saipan Tribune 9/30/99)

In (29), the weak pronoun occurs right after the adverb.

(29) a. Käna ha' yu’ sén-matai nai hu-li’i’ na más ki \$400.

almost EMP I AGR.extremely-die when AGR-see COMP more than $\$ 400$

'I was almost completely knocked out when I saw that [the bill] was more than \$400.' (Saipan Tribune 7/1/99)

b. Duru hit man-guput.

a.lot we AGR-party

'We partied a lot.' (Saipan Tribune 5/13/99)

c. Kulan ha' $y u$ ' i udu.

kind.of EMP I the mute

'I was kind of the mute one.'

Second, when the lexical head of the predicate is preceded by a functional head in its extended projection (in the sense of Grimshaw 2000), the weak pronoun can follow the predicate or occur right after the functional head. This situation arises, for instance, when a DP predicate is headed by a nonclitic determiner such as a quantifier, an interrogative pronoun, or a demonstrative. The weak pronoun can surface either after N (as in (30)) or after the determiner (as in (31)).

(30) a. Hafa na klasi-n taotao hao?

what? L sort-L person you

'What kind of person are you?'

b. Dos na ma'estra-n Chapanís häm.

two L teacher-L Japanese we

'We are two Japanese teachers.' 
(31) a. Hayi $y u^{\prime}$ na lahi?

who? I L man

'What kind of man am I?' (from a popular song)

b. Unu $y u$ ' na patgun gi hälum i sais na mañe'lu-hu.

one I L child LOC inside the six L siblings-AGR

'I was one child among my six brothers and sisters.' (Familia 4)

c. Meggai häm na peskadót.

many we L fisherman

'We were many fishermen.' (Cooreman 1983:4)

When an AP predicate is preceded by a degree word - which, following Abney (1987), I analyze as the head of DegP - the weak pronoun can occur either after A (as in (32a)) or after the degree word (as in (32b)). ${ }^{7}$

(32) a. Mämpus man-geftao hit um-apasiyi taotao hiyung.

too AGR-generous we INFIN-pay person outside

'We've been too generous in paying for outsiders.' (Saipan Tribune 10/14/99)

b. Mämpus hit man-espantáo.

too we AGR-scared

'We were horrified.' (Saipan Tribune 9/30/99)

Finally, when a VP predicate is preceded by an auxiliary (which I will locate arbitrarily in an abstract verbal head), the weak pronoun can follow either V (as in (33)) or the auxiliary (as in (34)).

(33) a. Hafa na ti siña kietu hao ya un-fan-osgi? what? COMP not can AGR.keep.still you and.then AGR-AP-obey

'Why can't you keep quiet and behave?' (I Tronkon Humugando 39)

b. Esta siña ha-bira gui' tatti gi tiyan-ña!

already can AGR-turn him back LOC stomach-AGR

'Suddenly he could turn (himself) back onto his belly!' (I Kareran Igu 4)

(34) a. Siña $y u$ ' um-o'mak!

can I AGR-swim

'I can swim!' (I Kareran Igu 4)

b. Kao siña $y u$ ' un-na'-chotchu sa' esta $y u$ ' góf-ñalang.

Q can me AGR-CAUS-eat because already I AGR.very-hungry

'Could you feed me, because I'm very hungry.' (Mannge' na Alaguan Kalamasa 5) (i).

${ }^{7}$ A more complex example from naturally occurring discourse that illustrates the same point as (32b) is given in

(i) Kulan mämpus yu' ha-na'-baba sininte-kku.

kind.of too me AGR-CAUS-bad feeling-AGR

'It seemed like it made me feel very bad.' (Cooreman 1983:189) 
(In (34b), there are two instances of the weak pronoun $y u$ ': the first follows the auxiliary siña 'can', and the second follows the adverb esta 'already'.)

The word order flexibility illustrated in (26)-(34) is classic $2 \mathrm{P}$ clitic behavior. It can be accommodated very poorly in an analysis that treats the material to the left of the weak pronoun as a syntactically independent maximal projection. (26c) and (27) make this point especially clearly. In (26c), what precedes the weak pronoun is a partial DP consisting of D plus an AP modifier but lacking NP, which surfaces to the right. In (27), what precedes the weak pronoun is a partial PP lacking the NP portion of its DP complement. In neither case could movement have led to the bifurcation of the larger DP or PP, since movement never has this effect (see also Chung 1998:286-291). Compare the pair of examples in (35), which show that movement in focus constructions cannot cause a DP to separate into D plus an AP modifier, on the one hand, and NP, on the other.

(35) a. I más amku' na chi'lu-hu palao'an kumékuentus yan i the most old L sibling-AGR female WH[NOM].AGR.speak.PROG with the principal. principal 'My oldest sister was talking to the principal.'

b. *I más amku' kumékuentus na chi'lu-hu palao'an yan i the most old WH[NOM].AGR.speak.PROG L sibling-AGR female with the principal.

principal

('My oldest sister was talking to the principal.')

I conclude that the material preceding the weak pronoun in these examples cannot be uniformly analyzed as a freestanding maximal projection, contrary to the claims of the syntactic approach outlined in section 3.1. Such an approach must therefore be rejected in its pure form.

\subsection{A Modified Syntactic Approach?}

At this point, one might wonder whether the syntactic approach of section 3.1 could handle the full range of evidence if it were revised to include some appeal to prosody. Numerous treatments of $2 \mathrm{P}$ clitics have attempted to give formal expression to the idea that "second position" is characterizable partly in syntactic and partly in prosodic terms. What interests me here is that in some of these treatments, the appeal to prosody is a repair strategy superimposed on a fundamentally syntactic account of the positioning of these forms. ${ }^{8}$ Halpern (1995), for instance, proposes that the placement of $2 \mathrm{P}$ clitics is determined "in the large" by the syntax and then fine-tuned by the operation of prosodic inversion. Bošković (2001) proposes that $2 \mathrm{P}$ clitics are positioned by syntactic operations alone, but certain clitics in syntactically permissible positions are filtered out as ungrammatical by the phonology.

\footnotetext{
${ }^{8}$ Not all treatments of 2P clitics share this property. See, for example, Anderson 1993, 2000, and Legendre 1996 for proposals in which the syntactic and prosodic characterizations of "second position" are in competition.
} 
Could a syntactic approach modified along these lines give a successful account of the placement of weak pronouns in Chamorro? I maintain that it could not. Section 4.3.1 discusses prosodic inversion; section 4.3.2, the issue of PF filters.

4.3.1 Prosodic Inversion In Halpern's (1995) theory of prosodic inversion, 2P clitics are the content of syntactic heads that are adjoined to the left edge of the clause. What makes these forms special is their prosodic subcategorization, which demands that they adjoin to the right of a prosodic word in the phonology. In syntactic structures in which some maximal projection has raised out of the clause to a position preceding the clitic, the clitic's prosodic subcategorization can be fulfilled without further ado: it simply attaches to the end of the prosodic word that immediately precedes it. In structures in which no raising has occurred and nothing precedes the clitic, prosodic inversion must intervene in order for the clitic's prosodic needs to be satisfied. This phonological operation causes the clitic to "trade places" with an adjacent prosodic word. ${ }^{9}$

If prosodic inversion were incorporated into the syntactic approach of section 3.1 , the resulting upgrade might look like this. Weak pronouns would, as before, be the content of syntactic heads that have raised to T. But now, only some types of predicate XPs would be permitted to raise to the specifier of T, where they would "protect" the weak pronoun from prosodic inversion. DP and PP predicates would be allowed to raise to T's specifier; VPs and APs would not.

On this view, clauses with a DP predicate, such as (12a), repeated here, would have the syntactic derivation sketched in (36).

(12) a. [Águaguat na patgun] gui'.

naughty $\mathrm{L}$ child he

'He's a naughty child.'

Notice that once the DP had raised to T's specifier, the weak pronoun would be free to attach to the end of the prosodic word immediately preceding it, which is enclosed in angled brackets.

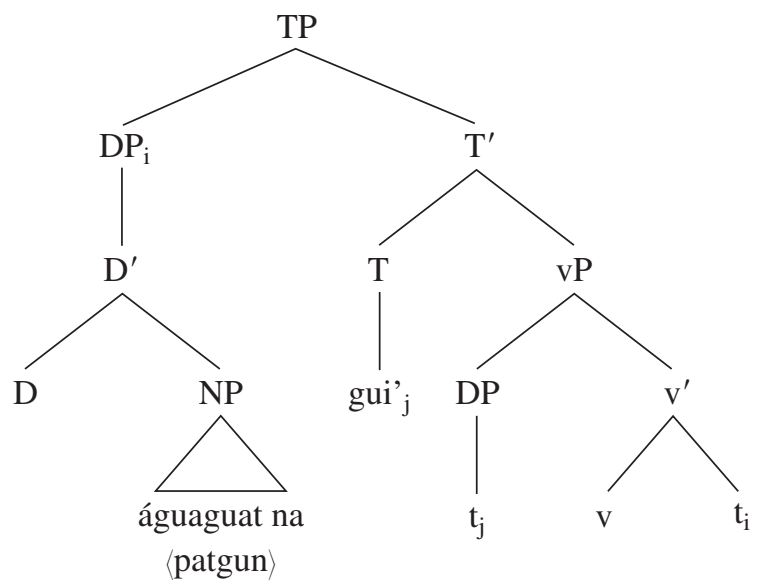

\footnotetext{
${ }^{9}$ Halpern (1995:17) allows for the possibility that in some languages, the clitic might invert with a prosodic unit different from the prosodic word. I do not pursue this possibility here. One could think of developing an alternative to
} 
Clauses with a VP predicate, such as (16a) (repeated here), would have a derivation in which T's specifier remained unoccupied.

(16) a. Malägu' gui' nuebu na kareta.

AGR.want she new L car

'She wants a new car.'

Prosodic inversion would then step in to reorder the weak pronoun with the prosodic word on its right, as shown by the arrow in (37).

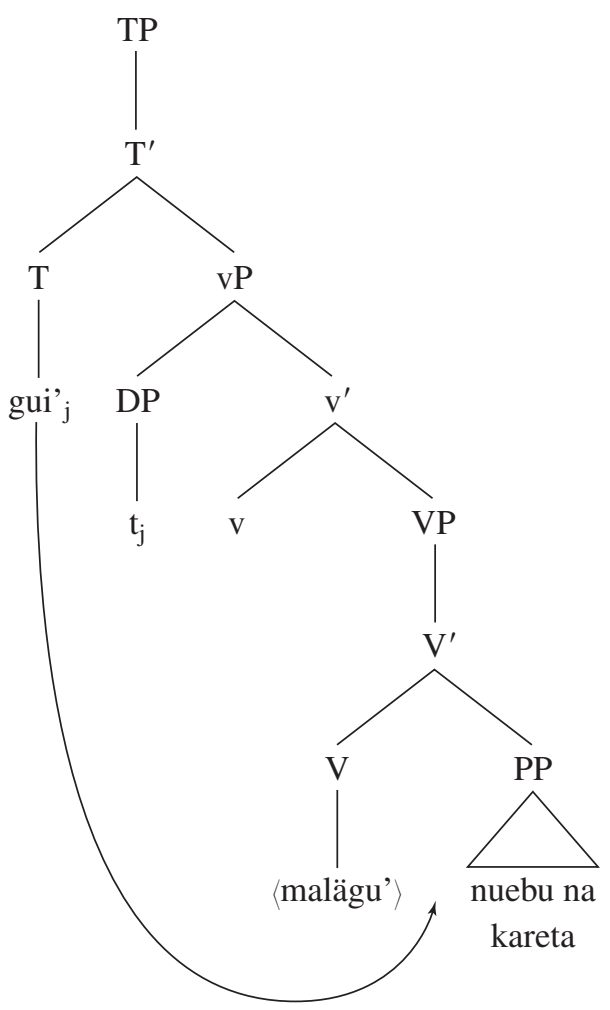

Such a proposal has one clear advantage over the original version of the syntactic approach in section 3.1. It accounts right away for the observation that weak pronouns cannot follow an unambiguous VP or AP, but must instead surface immediately to the right of V or A (see section 3.3). The crucial assumption is that VPs and APs cannot raise to a higher specifier, but must

the prosodic inversion analysis discussed in the text in which the prosodic unit involved in inversion was not the prosodic word, but the phonological phrase. Such an alternative would be able to handle the distribution of weak pronouns in examples such as (28), (32a), and (33). But there are other examples it would have great difficulty accounting for. See (11), (20), and the examples in section 6.3. 
instead remain in place, where their initial prosodic word would be targeted by prosodic inversion. Interestingly, there is independent support for this assumption in the patterning of $w h$-movement. In Chamorro, DPs and PPs can undergo wh-movement to the specifier of C, but VPs and APs cannot. The language has no constructions at all in which VP or AP has raised to a syntactic topic or focus position-no analogues of AP-preposing, VP-preposing, VP-clefting, and the like (Chung 1998:294-296). The complete absence of such constructions lends weight to the claim that what is wrong with examples like (18) is precisely that they would involve illegal syntactic movement.

However, a syntactic approach that included prosodic inversion would be unable to account for the full range of positional evidence discussed in section 4. I showed in section 4.1 that a weak pronoun cannot follow a DP predicate containing a possessor or postnominal modifier (see (20)), but must instead surface immediately to the left of $N$ (see (21)-(22)). An approach that included prosodic inversion could handle the well-formed (21)-(22): these examples would have a derivation in which the DP predicate failed to raise to T's specifier and prosodic inversion was forced to occur. But it could not account for the ill-formed (20), because it would have no way of preventing the entire DP predicate in such examples from raising to the specifier of T. Obviously, Chamorro has no language-specific aversion to leftward movement of DPs containing possessors or postnominal modifiers. The evidence from $w h$-movement in focus constructions makes this clear. Notice especially (38b), in which the focused negative DP must have raised to a position high enough to license the negative concord item ni mánunu ha' 'nowhere' (Chung 1998:272-273).
a. [I sapatos-ña si Juan] malingu,
ya
[si Maria] sumodda'.
the shoe-AGR Juan WH[NOM].AGR.disappear and.then Maria $\mathrm{wH}_{\mathrm{NOM}} \mathrm{NO}$.find 'It was Juan's shoes that were lost and it was Maria who found them.'
b. [Ni háyiyi ha' na istudiante-nña si Antonio] man-hanao ni mánunu ha'. not anyone EMP L student-AGR Antonio wH[NOM].AGR-go not anywhere EMP 'None of Antonio's students went anywhere.'

But then the inability of such DPs to raise to T's specifier, where they would surface to the left of the weak pronoun (20), remains unexplained.

I also showed in section 4.2 that when the lexical head of the predicate is preceded by a modifier or by a functional head in its extended projection (henceforth, MFX), a weak pronoun can follow the lexical head or occur immediately after the MFX. As it happens, when the predicate is VP or AP, an approach that included prosodic inversion could describe only the second of these options. Here is why. Recall that in this approach, VPs and APs would never raise to a higher specifier but would always remain in place. The weak pronoun, which would previously have raised to $\mathrm{T}$ and would hence occur at the far left, must therefore invert with the first prosodic word on its right. Now if the verb or adjective were immediately preceded by an MFX that formed an independent prosodic word, the weak pronoun would — obviously — invert with the MFX, since the two would be adjacent.

Significantly, the MFXs described in section 4.2 do indeed form independent prosodic words. This is shown, among other things, by the fact that they can support (other) enclitics even when 
they are clause-initial. Consider (29a), (29c), and the following examples, in which the clauseinitial MFX serves as host for the emphatic $h a^{\prime}$, a simple enclitic whose only prosodic need is that it must attach to the preceding prosodic word (cf. (39d)). The fact that the MFX can satisfy this need reveals that it is prosodically independent, and not-for instance-a proclitic (see section 2).

(39) a. Fiu ha' $y u^{\prime}$ makmata antis di alas sais.

often EMP I AGR.wake before o'clock six

'I very often wake up before six.'

b. Mämpus ha' banidosa.

too EMP AGR.pretentious

'She's just too pretentious.'

c. Siña ha' ta-li'i' i fondu.

can EMP AGR-see the bottom

'We can see the bottom!' (I Imang yan si Ando' 3)

d. Ha-mentiona put i hinemlo'-ña ha'.

AGR-mention about the health-AGR EMP

'He mentioned only his own health [not his wife's].'

An approach that included prosodic inversion would, therefore, have no trouble describing examples like (29), (32b), and (34), in which the weak pronoun occurs immediately after the MFX. See the derivation of (29b), which is given in (40).

(40)

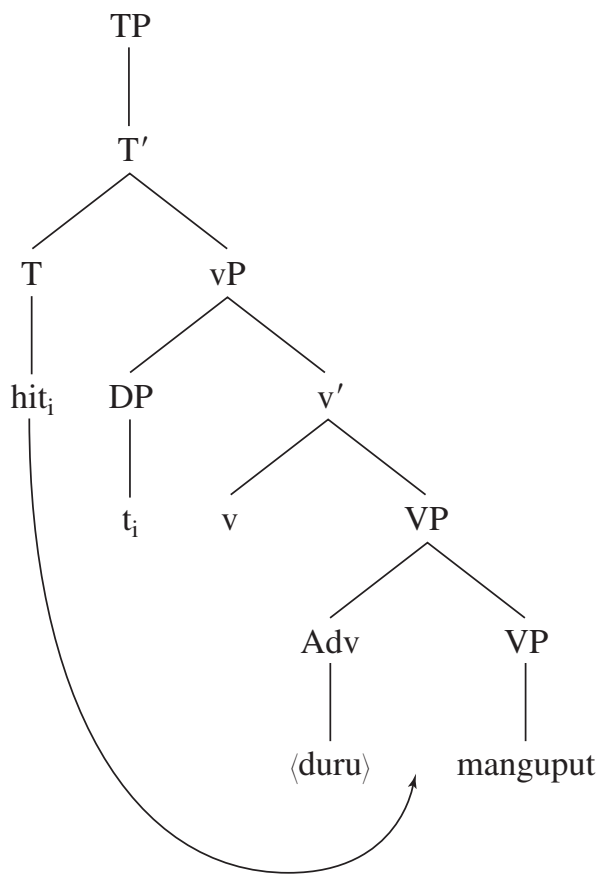


But precisely because the MFX forms an independent prosodic word, there would be no way of describing examples of type (28), (32a), and (33), in which the weak pronoun follows the verb or adjective. Prosodic inversion could lead to this result only if the MFX were prosodically dependent, so that the first prosodic word following the weak pronoun consisted of the MFX plus the verb or adjective. But the evidence argues that this cannot be so. The dilemma is especially acute in examples, such as (28a) and (41), in which the MFX's status as an independent prosodic word is validated by the emphatic enclitic $h a^{\prime}$ at the same time as the weak pronoun surfaces immediately after the verb.

(41) Fiu ha' man-malagu häm. often EMP AGR-run we

'We very often run.'

In sum, a syntactic approach that includes prosodic inversion still leaves some aspects of the placement of weak pronouns unaccounted for.

4.3.2 PF Filters Bošković (2001) develops an approach to 2P clitics in Serbo-Croatian in which these forms have two distinguishing properties. First, they can ambiguously be syntactic heads or the maximal projections of those heads. They can therefore undergo syntactic movement to a range of higher head or specifier positions. Second, they have a prosodic subcategorization that demands that they both follow an intonational phrase boundary and be separated from that boundary by a prosodically appropriate host. In the phonology, a clitic that finds itself anywhere except in second position within its intonational phrase cannot satisfy these requirements, and so is filtered out as ungrammatical. Such an approach claims that it is solely the syntax's responsibility to place a clitic in the position in which it is ultimately pronounced. The phonology's contribution is to impose additional, prosodic restrictions that certain clitics in syntactically well formed positions cannot satisfy.

Part of the appeal of Bošković's approach is that it succeeds in reconciling two generalizations concerning Serbo-Croatian clitics that might initially have seemed to be in conflict. First, every appropriate host for clitics in this language is a syntactic constituent that can be shown independently to occupy C or C's specifier (see, e.g., Progovac 1996). Second, the domain within which "second position"' is defined must—nonetheless — be characterized prosodically (see, e.g., Radanović-Kocić 1988, 1996).

Would weak pronouns in Chamorro be amenable to an approach of this sort? The answer is no. Where Chamorro differs from Serbo-Croatian is that the location of weak pronouns cannot be specified in syntactic terms, because there is no syntactically uniform characterization of their hosts ( = the material preceding them). Consequently, an approach in which these clitics are positioned in the syntax and then subjected to additional filters in the phonology would leave some grammatical instances of these forms unaccounted for.

We have already seen that the material preceding a weak pronoun is sometimes an independent maximal projection, but other times not a maximal projection or even a syntactic constituent. In (21), for instance, what precedes the weak pronoun is a partial DP that excludes the possessor. Consider again (21b). 
(21) b. Kao patgon-ña hao ädyu na ma'estra? Q child-AGR you that $\mathrm{L}$ teacher 'Are you that teacher's child?'

That the partial DP does not form a complete maximal projection is shown by the fact that it cannot undergo movement - for instance, to focus position. Compare the ungrammatical (42a-b).

(42) a. ?*[Mismu kareta-nñiha] ha' ma-sugun i famalao'an.

own car-AGR EMP AGR.PASS-drive the women

('The women's own car was driven.')

b. ??[Patgon-ña] mämaigu' i palao'an.

child-AGR AGR.sleep.ProG the woman

('The woman's child was sleeping.')

Similarly, in (26c) and (27), the material preceding the weak pronoun is a partial DP or PP that excludes the NP complement of D. On standard assumptions, this material does not form a syntactic constituent but rather consists of several constituents: D plus AP in (26c), for instance. Even more dramatic examples of nonconstituency will be presented in section 6 .

More generally, an approach that appeals to PF filters could extend to Chamorro only if weak pronouns always surfaced in positions in which the syntax could have placed them. But the evidence indicates that this is not so.

\section{A Prosodic Approach}

A broader point emerges from the discussion so far. Many theoretical accounts of $2 \mathrm{P}$ clitics proceed from the assumption that "second position" can be accurately, if informally, characterized as " after the first syntactic phrase or the first prosodic word.' Useful though this characterization might be elsewhere, it does not succeed in capturing the placement of weak pronouns in Chamorro. If "after the first syntactic phrase" were always an option for the placement of weak pronouns, examples of type (18) and (20) should be grammatical, but they are not. If the first syntactic phrase and the first prosodic word exhausted the options, examples such as (26c) and (28a) should be ungrammatical, but they are well formed. ${ }^{10}$

Clearly, what is needed to characterize the Chamorro notion of "second position" is a grouping larger than the prosodic word but different from syntactic constituency. The purpose of this section is to demonstrate that prosodic structure provides just such a grouping, namely, the phonological phrase.

Section 5.1 gives a brief introduction to prosodic structure. Section 5.2 focuses more narrowly on phonological phrases (henceforth, p-phrases). After surveying the architecture of the mapping

\footnotetext{
10 The first (i.e., leftmost) prosodic word in (26c) is $i$ más 'the most', while the first syntactic phrase is the entire DP $i$ más amku' na chi'luhu palao'an 'my oldest sister'. The first prosodic word in (28a) is käna 'almost', while the first syntactic phrase is the VP that includes this adverb: käna ha' mámatai ma'hu 'was almost dying of thirst'.
} 
constraints that parse the phonological string into p-phrases, I state the mapping constraint that I claim is responsible for p-phrasing in Chamorro. Section 5.3 shows that the notion of "second position" relevant to weak pronouns can be characterized prosodically: weak pronouns surface immediately after a p-phrase that is leftmost within its intonational phrase. The question of how weak pronouns come to occupy this position is addressed in section 7 .

\subsection{Prosodic Structure}

In prosodic hierarchy theory, prosodic structure is a layered hierarchical representation that organizes the phonological string into levels of successively more inclusive prosodic constituents (see, e.g., Selkirk 1980, 1986, Nespor and Vogel 1982, 1986, Hayes 1989, 1990, Inkelas 1990, Truckenbrodt 1995, 1999). Because this representation is a kind of constituent structure, every prosodic constituent is fully nested within the (unique) constituent that immediately dominates it, with no incongruity or overlap permitted (Selkirk 1986:384; but see Hyman, Katamba, and Walusimbi 1987 for a potential counterexample). In addition, prosodic structure is widely believed to conform to three more specialized design principles, which I summarize as follows.

The prosodic hierarchy. Prosodic structure consists of different types of prosodic constituents whose hierarchical arrangement reflects their ordering on a prosodic hierarchy. Following Selkirk (1986) and Inkelas (1990), I assume a hierarchy consisting of four constituent types - the prosodic word, the p-phrase, the intonational phrase (henceforth, i-phrase), and the utterance-ordered as shown in (43).

(43) The prosodic hierarchy

Utterance

Intonational phrase (i-phrase)

Phonological phrase (p-phrase)

Prosodic word

Strict layering. In prosodic structure, every constituent of a given type is immediately dominated by a constituent of the next higher type on the hierarchy. For instance, every prosodic word is immediately dominated by a p-phrase; every p-phrase is immediately dominated by an i-phrase; and so on. Recursive categories are not allowed.

Exhaustivity. In prosodic structure, each constituent type imposes an exhaustive parsing on the phonological string. So the string is exhaustively parsed into prosodic words; into p-phrases; and so on.

In what follows, I adopt the reconceptualization of these design principles developed by Inkelas (1990). In her version of prosodic theory, clitics and affixes are prosodic nonconstituents that adjoin to their hosts, thereby creating prosodic structures that violate strict layering and exhaustivity in the form in which they were just described (see also Zec and Inkelas 1991). To illustrate, the Chamorro emphatic enclitic $h a$ ', which attaches to a preceding prosodic word, participates in prosodic structures like (44a). The Tzotzil enclitic un, which Aissen (1992) claims is attached to a preceding i-phrase, participates in prosodic structures like (44b). 
(44) a. Chamorro
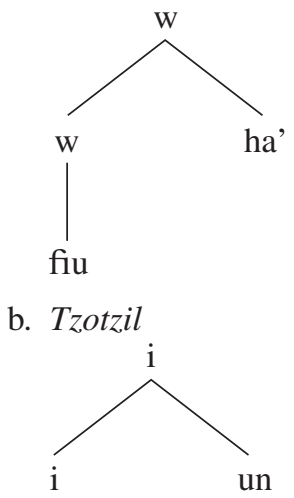

Notice that both (44a) and (44b) violate strict layering, assuming — with Inkelas — that adjunction creates a recursive structure in which the host constituent is immediately dominated by a prosodic constituent of the same type. ${ }^{11}$ Further, (44b) violates exhaustivity, since the enclitic un does not form part of any prosodic word or any p-phrase.

As Inkelas observes, the deeper issue raised by these limited violations of the design principles is how prosodic nonconstituents, such as clitics, are incorporated into higher prosodic structure. The solution that she pursues is to "take the intuition behind" strict layering and exhaustivity "and apply it instead to the algorithms which parse strings into prosodic constituents" (1990: 269). Here I follow Inkelas in analyzing clitics as prosodic nonconstituents that adjoin to their hosts, so it is important to me that structures of the type (44) be allowed by the design principles that regulate prosodic structure. I therefore adopt her Generalized Strict Parsing Condition (henceforth, Strict Parsing), which is intended to replace strict layering and exhaustivity. This condition continues to require that all prosodic words in the string must be grouped into p-phrases, all pphrases must be grouped into i-phrases, and so on. But it says nothing about clitics and other prosodic nonconstituents.

\section{(45) Generalized Strict Parsing Condition}

Parsing algorithms must group all phonological constituents of type $i-l$ into constituents of type $i$. (Inkelas 1990:271)

For a little more discussion, see section 7.

It should be abundantly clear by now that prosodic structure is organized differently from syntactic constituent structure, whatever the details of the syntactic structure assumed. As a concrete illustration of the differences, I give in (46) and (47) the syntactic and prosodic structures that I claim are associated with the Chamorro sentence (19a).

\footnotetext{
11 This assumption is by no means necessary, as the segment theory of adjunction makes clear.
} 
(46) Syntactic structure

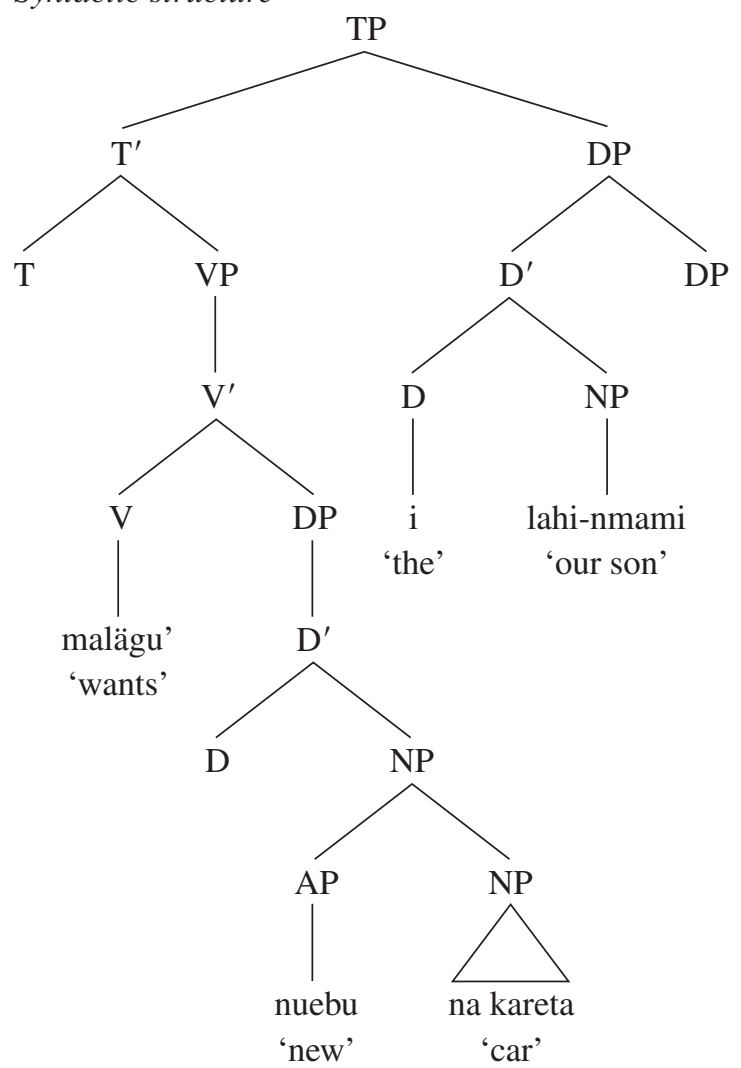

(47) Prosodic structure

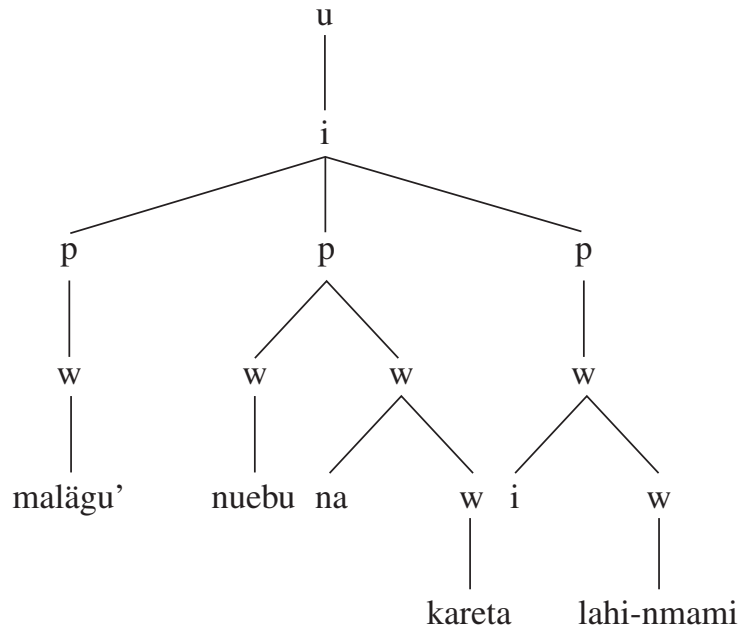


In the clause structure shown in (46), which is motivated in detail in Chung 1998 and which I assume henceforth, the specifier of TP is occupied by the subject, the specifier of DP is occupied by the possessor, and these specifiers are realized to the right of their heads.

It should be emphasized that nothing in the prosodic account of weak pronouns to be developed below depends crucially on the assumption that Chamorro clause structure looks like (46) as opposed to, say, (15). This is because the key constraint that maps syntactic constituency into prosodic constituency is insensitive to many hierarchical relations in syntactic structure, including the relative prominence of subject versus predicate. Therefore, whether one's point of departure is a clause structure like (46) or one like (15), the same prosodic structure will emerge, as interested readers can easily verify for themselves.

\subsection{P-Phrasing in Chamorro}

How is the phonological string parsed into prosodic constituents of each type? For the constituent types at the extremes of the hierarchy, the utterance and the prosodic word, the answer is relatively straightforward. Utterances "normally correspond to full sentences" (Hayes 1989:219). Prosodic words typically correspond to syntactic heads. Here I assume that individual lexical entries stipulate whether their phonological instantiation is an independent prosodic word. When this assumption is combined with Inkelas's (1990) view of cliticization and affixation, the result is that the phonological string created by late lexical insertion comes already parsed into prosodic words (see Selkirk 1986 for a different approach).

The situation is more fluid for i-phrases. The standard view of i-phrases, due to Selkirk and others, is that they are "sense units" whose edges are determined semantically but can shift depending on speech rate and other phonetic factors. In an attempt to control this variability, the discussion here is restricted to very simple Chamorro clauses which-I claim — consist of exactly one i-phrase. Some more complex sentence types are investigated in section 6.3.

P-phrases are the prosodic constituents that conform most clearly to the dictum that prosodic structure is calculated from syntactic structure but not isomorphic to it. The consensus emerging from previous research is that the phonological string is parsed into p-phrases by language-specific mapping constraints that refer directly to syntactic constituent structure. These mapping constraints are assumed to have the following architecture (see the references cited below and Truckenbrodt 1999):

1. The mapping constraints refer to the cross-categorial notions of X-bar theory but not to specific syntactic category names (see, e.g., Clements 1978, Selkirk 1986, Hayes 1989).

2. Consistent with Selkirk's (1986) end-based theory of prosodic domains, the mapping constraints align the left or right edges of XPs with the left or right edges of p-phrases (see also Chen 1987).

3. It is sometimes observed that the mapping constraints "see" lexical categories and their projections but not functional categories or their projections (Selkirk 1986; see also Hayes 1989). I will return to this observation immediately. 
4. Finally, in some languages, the mapping constraints ignore the edges of certain adjectival or adverbial modifiers, and in this sense treat them as not instantiating their own maximal projections (see, e.g., Clements 1978, Chen 1987, Selkirk and Tateishi 1991). This too is an observation that I will return to.

The overall result is that the mapping constraints parse the string into units larger than the prosodic word but not isomorphic to syntactic constituents. In fact, one argument standardly given for analyzing some phenomenon in terms of p-phrases is that it is sensitive to constituents larger than the prosodic word that are demonstrably not syntactic constituents. Since I have just argued that Chamorro weak pronouns exhibit exactly this sensitivity, let me now ask whether their placement can be characterized in terms of p-phrasing. Is there a mapping constraint that would parse the material preceding a weak pronoun into exactly one p-phrase?

I claim that there is such a mapping constraint, and it is stated as follows:

(48) Align the left edge of XP with the left edge of a p-phrase.

The same mapping constraint is also found in Ewe and Japanese; for discussion, see Clements 1978, Selkirk 1986, and Selkirk and Tateishi 1991.

The usual assumption is that mapping constraints such as (48) interact with exhaustivity (here, Strict Parsing) to produce a full parse of the string into p-phrases. Before I can illustrate this for Chamorro, two issues of implementation must be settled.

The first issue is how the Chamorro version of (48) responds to syntactic structures in which some constituent is adjoined to a maximal projection. Assuming the segment theory of adjunction (Chomsky 1986), there are two principled options. The adjoined constituent might count as outside the host XP, because it is not contained within every segment of XP and therefore is not dominated by XP. On the other hand, the adjoined constituent might count as inside XP, because it is contained within at least one of XP's segments. Interestingly, it appears that languages can differ with respect to which option they employ. According to Truckenbrodt (1999:235), the mapping constraints of Tohono O'odham select the first option. I think it likely that mapping constraints that ignore the edges of certain modifiers (see point 4 above) do so because they have selected the second option; see Selkirk and Tateishi 1991 on Japanese, as well as Clements 1978 on Ewe and Chen 1987 on Xiamen.

As far as Chamorro is concerned, substantial evidence argues that the syntax makes use of both interpretations of adjunction structures: adjuncts to XP are treated as inside XP in some contexts, but outside XP in others (Chung 1998:325-332). ${ }^{12}$ Building on this, I make the following claim:

\footnotetext{
${ }^{12}$ More precisely, for syntactic purposes, Chamorro constituents adjoined to a lexical XP are treated as inside XP; constituents adjoined to a functional XP are treated as outside XP. The proposal in the text claims that Chamorro-specific mapping constraints freely employ both interpretations, disregarding whether the host XP is lexical or functional.

Hubert Truckenbrodt has suggested to me that in line with some ideas advanced by Soh (2001:71), one could think of proposing a different internal structure for Chamorro DPs in which a prenominal adjective would head one of the projections in the (highly articulated) functional layer above NP. If so, the effects of (49) could perhaps be subsumed under (50), which is discussed later in the text. I am unable to pursue this very interesting suggestion here.
} 
(49) For the purposes of Chamorro mapping constraints, a constituent adjoined to XP can be treated as inside or outside XP.

The second issue is how the Chamorro version of (48) responds to functional projections. Recall from point 3 above that mapping constraints are sometimes said to ignore functional categories and their projections. The observation is surely connected to a different generalization: for whatever reason, the "grammatical" elements that are the content of functional heads are normally prosodically dependent_clitics or affixes. If we accept this, then the possibility arises that mapping constraints might actually "see" functional projections and attempt to parse them. But the parses would normally be unsuccessful, because functional material normally cannot form a prosodic constituent on its own.

As a matter of fact, the content of functional heads in Chamorro is not always prosodically dependent. While some functional items are proclitic (e.g., the definite article $i$, the indefinite article $u n$, some prepositions, certain inflectional elements), others are independent prosodic words (e.g., demonstratives, the degree words más 'more, most' and mämpus 'too', auxiliaries). The placement of weak pronouns with respect to the latter leads me to assert the following:

(50) For the purposes of Chamorro mapping constraints, a functional head can be treated as inside or outside the lexical XP in its extended projection.

This statement declares, in essence, that constraint (48) can choose to "see" functional projections or to ignore them.

\subsection{The Placement of Weak Pronouns}

I now claim that the position of weak pronouns in Chamorro can be characterized in purely prosodic terms: these $2 \mathrm{P}$ clitics surface immediately after the first $\mathrm{p}$-phrase within the next higher prosodic domain (which is, of course, the i-phrase). In Inkelas's (1990) terms, weak pronouns have the prosodic subcategorization shown in (51): they adjoin to the right of a p-phrase that is leftmost within its i-phrase. ${ }^{13}$

(51) $\left[{ }_{i}[\mathrm{p}[\mathrm{p}]-]\right.$

Similar proposals have been made for Serbo-Croatian clitics by Radanović-Kocić $(1988,1996)$ and Bošković (2001) and for Ancient Greek clitics by Hock (1996), as was mentioned earlier.

To see how the proposal works, consider first the schematic syntactic structures in (52). These trees represent the internal structure of the leftmost XP of the clause, where-consistent with (50) - this maximal projection can be taken to be the leftmost lexical XP or the leftmost $\mathrm{XP}$ of any sort. The left parentheses on the first line below the trees represent the partial pphrasing imposed by mapping constraint (48). The parentheses on the second line show how the

\footnotetext{
${ }^{13}$ It is unclear to me whether the reference to the left edge of the i-phrase in (51) violates the locality restrictions that one might want to impose on prosodic subcategorization. In any event, some such reference must be made if one is going to characterize "second position", in prosodic terms. I therefore adopt (51) without further comment.
} 
parse is completed, assuming Strict Parsing and glossing over potential complications introduced by prosodically dependent items (on which see section 6).

(52) a.

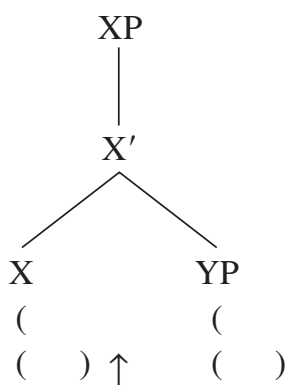

b.

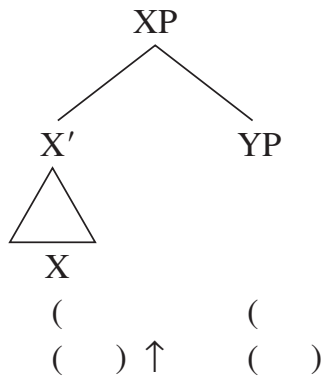

XP has a complement YP in (52a) and a specifier YP in (52b). In both cases, constraint (48) maps the left edge of XP and the left edge of YP onto left edges of p-phrases. Once the parse is completed, the result is two p-phrases, the first containing the phonological substring that instantiates $\mathrm{X}$ and the second, the substring that instantiates YP. Because the first p-phrase is leftmost within the i-phrase corresponding to the clause, the weak pronoun is adjoined to its right and surfaces in the position marked by the arrow. For (52a), the result is the pattern illustrated in (16)-(17), in which a weak pronoun occurs immediately after V or A even when a complement or adjunct follows. Notice that the ill-formed (18), in which the weak pronoun occurs after an unambiguous VP or AP, could not be generated. For (52b), the result is the pattern illustrated in (21), in which the weak pronoun occurs immediately after $\mathrm{N}$ (more precisely, $\mathrm{D}^{\prime}$ ) and precedes the possessor. Once again, the ill-formed (20), in which the weak pronoun follows the entire DP, could not be produced.

Next, consider (53), in which XP has YP adjoined to its right.

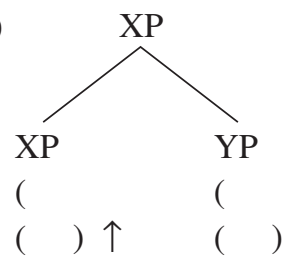


As before, constraint (48) maps the left edge of XP and the left edge of YP onto left edges of p-phrases, leading to the complete p-phrasing shown on the second line. Because the first pphrase is also leftmost within the i-phrase corresponding to the clause, the weak pronoun is adjoined to its right and surfaces in the position marked by the arrow. This is the pattern illustrated in (22).

Consider now the schematic trees in (54), which show XP with a constituent $\mathrm{Z}$ adjoined to its left.

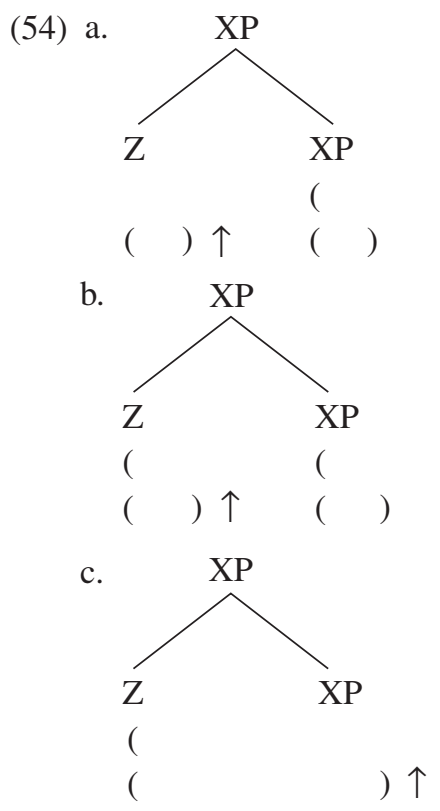

Here the interpretation of adjunction structures (49) comes crucially into play. If $\mathrm{Z}$ is treated as outside XP, constraint (48) will map the left edge of XP onto the left edge of a p-phrase, as shown in (54a). Additionally, if $\mathrm{Z}$ is a maximal projection, the constraint will map Z's left edge onto the left edge of another p-phrase, as in (54b). Either way, the result is a p-phrasing that will cause the weak pronoun to be realized immediately to the right of $\mathrm{Z}$. On the other hand, if $\mathrm{Z}$ is treated as inside XP, then constraint (48) will align the left edge of XP with the left edge of a p-phrase as shown in (54c). No additional p-phrases will be instantiated because the lower segment $\mathrm{XP}$ does not count as a maximal projection distinct from the higher segment. The result is a pphrasing that will cause the weak pronoun to be realized immediately to the right of XP. These are exactly the options seen earlier in $(26 a-b)$ and (28)-(29), in which the weak pronoun could follow XP or occur immediately after a modifier left-adjoined to XP.

Thanks to the stipulation in (50) concerning functional heads, the p-phrasing is similarly flexible when XP is lexical and preceded by a functional head $\mathrm{F}$ in its extended projection (FP). See the trees in (55), which correspond to the two options illustrated in (30)-(34). 
(55) a.

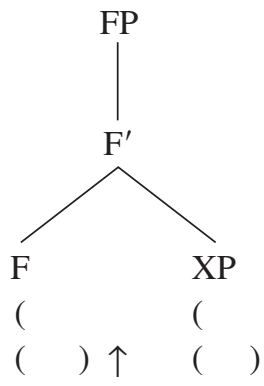

b.

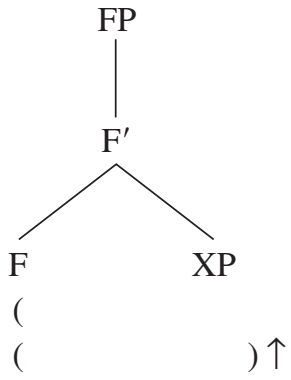

Notice, finally, that the proposal straightforwardly accounts for the position of weak pronouns in the challenging examples (26c) and (27). The leftmost maximal projection in these examples has the internal structure schematized in (56).

(56)

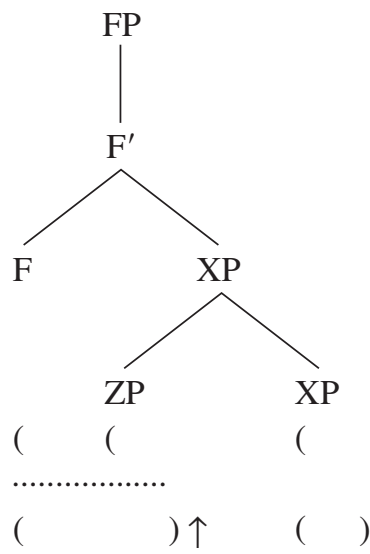

Here, just as in (55), there are in principle two (relevant) ways that the structure could be parsed: with the phonological substrings instantiating $\mathrm{F}$ and ZP in the same p-phrase, or in different $\mathrm{p}$ phrases. What is special about examples (26c) and (27) is that the definite article $i$ and the preposition ginin 'from', which are the content of $\mathrm{F}$, are simple proclitics that must adjoin to the following prosodic word. Therefore, even if the structure is parsed as shown in the first line below tree (56) (compare (55a)), the prosodic dependence of these items would ultimately lead to the 
p-phrasing shown below the dotted line. ${ }^{14}$ In this phrasing, the first p-phrase-which is also leftmost within its i-phrase - consists of the substring instantiating $\mathrm{F}$ and the left-adjoined modifier ZP. The weak pronoun surfaces immediately after this substring, exactly as predicted.

In short, the system of p-phrasing presented in (48)-(50), together with the claim that the "second position" relevant to weak pronouns is defined in terms of p-phrases, succeeds in giving an exceptionless account of the surface location of these forms. (For some discussion of the placement of weak pronouns in coordinate structures, see the appendix.)

\section{Further Evidence}

A difficult question must now be confronted. What independent evidence supports the claim that this account is prosodic? To restate, we already know that the constituents parsed by mapping constraint (48) are not syntactic constituents. How do we know that they are prosodic constituents?

In the best world, the p-phrasing that I proposed for Chamorro would be validated by independent evidence from Chamorro phonology - for instance, from postlexical processes affecting tone, intonation, or duration that have the p-phrase as their domain of application. It is unfortunate that I know of no such evidence.

Still, there are less direct methods of strengthening the case for the fundamentally prosodic character of my proposal. Below I use the design of prosodic structure to argue that the constituents parsed by (48) behave as though they are situated in this structure above the level of the prosodic word but below the level of the i-phrase. In other words, they behave exactly like p-phrases. Section 6.1 shows that these constituents can consist of more than one prosodic word. Section 6.2 shows that their edges must respect the integrity of the prosodic word. Finally, section 6.3 suggests that the identity of the constituent selected as the leftmost such constituent shifts with the left edge of the i-phrase containing it.

\subsection{P-Phrases Can Consist of Several Prosodic Words}

If the constituents parsed by (48) are indeed p-phrases, they should be located above the level of the prosodic word in prosodic structure. They should therefore be able to consist of more than one prosodic word. In section 4.3.1, I discussed some evidence from the distribution of simple clitics that bears out this expectation. Consider again (41), which is repeated here.

(41) Fiu ha' man-malagu häm.

often EMP AGR-run we

'We very often run.'

Here the location of the weak pronoun reveals that the constituent parsed by (48) consists of the

\footnotetext{
${ }^{14}$ A second p-phrasing is also possible: the entire FP might correspond to a single p-phrase. Examples collected in elicitation suggest that it is indeed possible for a weak pronoun to surface after the entire FP. In naturally occurring discourse, it seems (impressionistically) more common for the weak pronoun to occur immediately after the modifier, as discussed in the text.
} 
entire adverb-plus-verb grouping. At the same time, the location of the emphatic $h a$ ', a simple enclitic, reveals that the adverb fiu 'often' forms an independent prosodic word. (Recall that $h a$ "s only prosodic need is that it must adjoin to the preceding prosodic word.) The conclusion seems clear that the adverb-plus-verb grouping consists of more than one prosodic word-just as expected if this grouping is a p-phrase.

The claim that constituents parsed by (48) can consist of several prosodic words is further supported by evidence from the morphophonology. Prosodic words in Chamorro are distinguished by the fact that they bear primary stress, which is calculated from the right. Among the many Chamorro processes sensitive to primary stress is the reduplication that realizes progressive aspect. When a predicate XP in Chamorro is inflected for progressive aspect, the inflection is realized on the leftmost prosodic word instantiating the XP, via reduplication of its primarily stressed $\mathrm{CV}$ (i.e., the onset and nucleus of the primarily stressed syllable, but not the coda). This reduplication is illustrated in the examples in (57), which also show that the affected prosodic word can be of any category type. In (57a), reduplication affects a verb (underlined); in (57b-c), an adjective; and in (57d), a noun. In (57e), the preposition ginin 'from' and the definite article $i$ are proclitics (see section 5.3), so reduplication affects the prosodic word consisting of these dependent items and the noun to which they are adjoined.

(57) a. Ni hagu mismu ti un-li'i' amanu un-hanánagui.

even you self not AGR-see where? AGR-go.to.PROG

'Even you yourself do not see where you are headed.' (Saipan Tribune 11/11/98)

b. $\underline{\text { Ti }}$ atrasásao.

not AGR.late.PROG

'He's never late.'

c. Á'aguaguat ha' gui' na patgun esta pa'gu.

naughty.PROG EMP he $\mathrm{L}$ child until now

'He's still a naughty child.'

d. Ma'estrótro-nña ha' si Juan si Mr. Perez?

teacher-AgR.PROG EMP Juan Mr. Perez

'Is Mr. Perez still Juan's teacher?'

e. Ginin $\underline{i}$ gima'-yúyu'us si nana-ña.

from the house-God.PROG mother-AGR

'Her mother was coming from the church.' (Dibota 8)

Importantly, reduplication can affect only the leftmost prosodic word instantiating the predicate XP. Attempts to realize the inflection on any prosodic word farther to the right are firmly rejected as ungrammatical. Compare $(57 \mathrm{c}-\mathrm{d})$ with $(58 \mathrm{a}-\mathrm{b})$.

(58) a. *Águaguat (gui’) na pápatgun ha' esta pa'gu.

naughty he L child.PROG EMP until now

('He's still a naughty child.') 


\section{b. *Ma'estro-nña ha' si Juájuan si Mr. Perez? teacher-AGR EMP Juan.PROG Mr. Perez}

('Is Mr. Perez still Juan's teacher?')

The point of interest is that, alongside (57c), examples like the following are well formed:

(59) Á'aguaguat ha' na patgun gui' esta pa'gu. naughty.PROG EMP L child he until now 'He's still a naughty child.'

In (59), the location of the weak pronoun reveals that the constituent parsed by (48) is the entire adjective-plus-noun grouping. But the reduplication simultaneously reveals that the adjective águaguat 'naughty' is an independent prosodic word. (Had the combination of adjective and noun formed a single prosodic word, that word's primary stress would have fallen on the initial syllable of patgun 'child'; compare (58a).) Once again, the conclusion seems clear that the adjective-plusnoun grouping consists of several prosodic words-just as expected if this grouping is a p-phrase.

\subsection{P-Phrases Must Respect the Integrity of Prosodic Words}

Because prosodic structure is a kind of constituent structure, the edges of constituents at a given level must align with edges of constituents at all lower levels. It is therefore impossible for the edge of a p-phrase to interrupt a prosodic word. The claim that p-phrasing must respect the integrity of prosodic words generates an expectation: if mapping constraint (48) does indeed parse the string into p-phrases, its effect should be suspended just in case it would place the edge of a p-phrase in the middle of a prosodic word.

Chamorro supplies two typologically unusual sorts of evidence bearing on this prediction, which I now discuss. The first involves proclitic verbs; the second, a productive means of deriving proclitic nouns.

6.2.1 Proclitic Verbs Chamorro has a handful of verbs that are simple proclitics, by which I mean that they are prosodic nonconstituents that must be adjoined to the prosodic word immediately to their right. One such verb, falak 'go to', obligatorily selects a goal as its complement. Consider:

(60) a. Pues bai u-falak i tenda. then AGR-go.to the store 'Then I'll go to the store.' (Sinko na Famagu'on 21)

b. malak manu i lahi-ña AGR.go.to where? the son-AGR

'[The mother didn't see] where her son had gone.' (Cooreman 1983:82)

That falak does not form an independent prosodic word is established by its failure to be directly affected by the reduplication that realizes progressive aspect (see section 6.1). What gets reduplicated instead is the primarily stressed CV of (what is evidently) the first prosodic word of the 
goal. This distinctive pattern is illustrated in (61) with progressive imperatives, which are quite common in Chamorro. Reduplication affects the primarily stressed CV of a directional adverb in (61a), a noun in (61b), and an adjective in (61c).

(61) a. Falak tátatti.

go.to back.ProG

'Be going (i.e., keep on going) back!'

b. Falak i gimáma'-ña.

go.to the house-AGR.PROG

'Be going (i.e., keep on going) to his house!'

c. Falak $\underline{i}$ chächagu' na guma'.

go.to the far.ProG $\mathrm{L}$ house

'Be going (i.e., keep on going) to the farthest house!'

If we continue to assume that progressive aspect is realized on the leftmost prosodic word that instantiates the predicate XP, the natural inference is that falak, like the definite article $i$ in (61b-c), is a proclitic. The internal structure of the leftmost prosodic word in (61c) - the word affected by reduplication-is therefore as shown in (62).

(62)

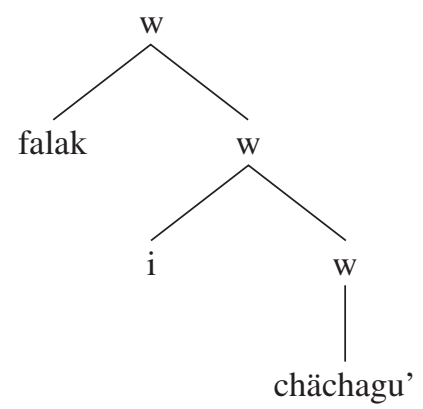

What is the fate of constituents parsed by (48) in VPs headed by falak? Under normal circumstances, one would expect the left edge of VP and the left edge of the goal-both maximal projections - to be aligned with left edges of groupings whose exact nature is under discussion. But when $\mathrm{V}$ is instantiated by the proclitic falak, the left edge of the second grouping would violate the integrity of a prosodic word, so if the groupings are indeed p-phrases, that parse should be suspended. This is what happens. The ill-formedness of the placement of the weak pronoun in (63) confirms that the constituents parsed by (48) cannot violate the integrity of a prosodic word.

(63) *Malak $y u^{\prime}$ i snack bar. AGR.go.to I the snack bar

('I went to the snack bar.')

Instead, the first constituent parsed by (48) encompasses falak and the first prosodic word of the goal, as is revealed by the position of the weak pronouns in (64). 
(64) a. Malak i snack bar $y u^{\prime}$. AGR.go.to the snack bar I 'I went to the snack bar.'

b. Malak ädyu yu’ i gima' ni ginin sumásaga yu' istaba. AGR.go.to that I the house COMP IMPERF AGR.stay.PROG I used.to 'I went to that house where I used to live.'

This is precisely the outcome expected if the constituents parsed by (48) are prosodic constituents-specifically, p-phrases.

6.2.2 Proclitic Nouns More dramatic evidence pointing to the same conclusion is supplied by the patterning of proclitic nouns.

In Chamorro, possessed Ns register the presence of a following possessor in one of two ways (Chung 1998:48-50). Either the possessed N exhibits person-number agreement with the possessor, as in the examples cited in section 4.1; or the possessed $\mathrm{N}$ is inflected for the postnominal form of the so-called linker. (In its postnominal form, the linker is realized as $-n$ on vowelfinal stems and unpronounced otherwise.) What concerns me here is that the second option has prosodic consequences: the postnominal form of the linker converts the noun into a simple proclitic that must adjoin to the following prosodic word. To put the point differently, the linker productively derives proclitic nouns from nouns whose lexical entries identify them as independent prosodic words. The construction is, in some ways, reminiscent of the construct state in Semitic languages.

Consider the examples in (65), in which possessed nouns followed by various sorts of possessors (in brackets) are inflected for the linker.

(65) a. i ma'estru-n [Carmen] the teacher-L Carmen

'Carmen's teacher (lit. the teacher of Carmen)'

b. i gapitulu-n [i patgon-ña si Carmen] the hair-L the child-AGR Carmen

'Carmen's child's hair (lit. the hair of the child of Carmen)'

c. mantika ginin katni-n [guäka yan bäbui]

fat from meat-L cow and pig

'beef and pork fat (lit. fat from meat of cows and pigs)' (Saipan Tribune 1/7/99)

d. Esta mu-nä'lu tatti i hinemlu' [ekonomia-n [tano'-ta]]. already AGR-return back the health.L economy-L land-AGR

'The health of the economy of our island has already rebounded.' (Saipan Tribune 10/26/99)

Once again, evidence for the prosodic dependence of these inflected nouns comes from their failure to be directly affected by the reduplication that realizes progressive aspect. Instead, what gets reduplicated is the primarily stressed CV of (what is evidently) the first prosodic word of the possessor. This is shown in (66). 
(66) a. sa' i puti-n [i aga'gága'-ña $]$

because the hurt-L the throat-AGR.PROG

'because of his throat's still being sore'

b. Ma'estru-n [Juájuan] ha' si Mr. Perez?

teacher-L Juan.PROG EMP Mr. Perez

'Is Mr. Perez still Juan's teacher?'

Note especially (66b), which forms a minimal pair with the ungrammatical (58b). The difference is that the possessed noun in (58b), which exhibits person-number agreement with the possessor, is an independent prosodic word, whereas the possessed noun in (66b) is inflected for the linker, and therefore a proclitic.

With this information in hand, let us reconsider the fate of the parsing imposed by (48) on DPs in which a possessed noun is followed by a possessor. The expected situation, of course, is for the left edge of the entire DP and the left edge of the possessor to be aligned with left edges of the groupings that I claim are p-phrases. We have already seen (in section 4.1) that when the possessed noun exhibits person-number agreement with the possessor, this phrasing is strictly enforced. What happens when the possessed noun is inflected for the linker, and therefore prosodically dependent?

Here the expectations are different. The left edge of the second grouping would fall in the middle of the prosodic word formed by the proclitic noun and its host, so if the groupings are actually prosodic constituents - p-phrases - that second parse should be called off. The facts reveal that this is indeed so. The constituents parsed by (48) cannot violate the integrity of a prosodic word, as can be seen from the placement of the weak pronouns in the ungrammatical $(67 \mathrm{a}-\mathrm{b})$.

(67) a. *Kao ma'estra-n hao [i chi'lu-hu]?

Q teacher-L you the sibling-AGR

('Are you my sister's teacher?')

b. *Taotao $y u^{\prime}$ [San Roque na songsung].

person.L I San Roque L village

('I'm a person of San Roque village.')

Instead, the first constituent parsed by (48) encompasses - at least - the possessed noun and the first prosodic word of the possessor. ${ }^{15}$ Consider the placement of weak pronouns in the following examples:

(68) a. Kao ma'estra-n [i chi'lu-hu] hao?

Q teacher-L the sibling-AGR you

'Are you my sister's teacher?'

\footnotetext{
${ }^{15}$ Examples of type (68b-d) are particularly clear illustrations of the claim that the material preceding a weak pronoun does not form a syntactic constituent. Consistent with this, the weak pronoun cannot be replaced by a full DP.
} 


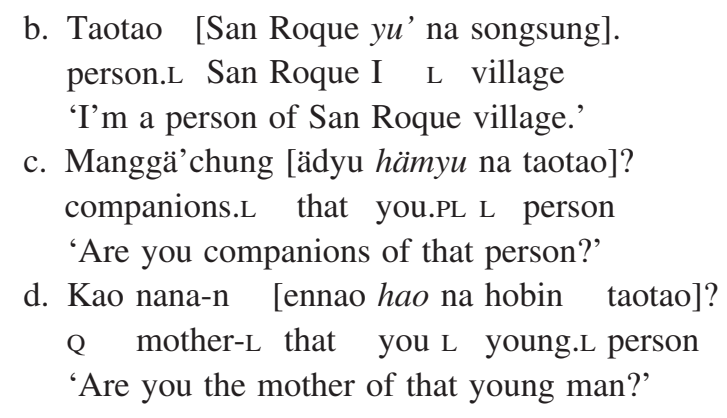

This is exactly what is predicted if the constituents parsed by (48) are p-phrases.

The chain of expectations created here can be taken further in two ways. Notice first that the options for parsing DPs containing a possessor are expanded if the possessor itself contains a prenominal modifier, or is headed by a $\mathrm{D}$ whose content forms an independent prosodic word. Under these circumstances, (49)-(50) come into play, and mapping constraint (48) should lead to two parses. In the first, the proclitic possessed noun should be grouped together with the possessor's prenominal modifier or D but separately from the NP portion of the possessor. This parse, which treats adjoined or functional material as "outside," leads to examples such as (68b-d). In the second parse, the proclitic possessed noun should be grouped with all material up to and including the $\mathrm{N}$ of the possessor. This "inside" parse seems possible as well, as the following elicited examples suggest:

(69) a. ?Taotao [San Roque na songsung] yu'. person.L San Roque L village I 'I'm a person of San Roque village.'

b. Kao mañaina-n [ädyu i hobin na palao'an] hämyu? Q parents-L that the young $\mathrm{L}$ woman you.PL 'Are you the parents of that young woman?'

Second, notice that it should be possible for the proclitic verb falak to select as complement a goal headed by a possessed noun that is itself proclitic. If so, the first constituent parsed by (48) — the first p-phrase-should encompass falak, the possessed noun, and the first prosodic word of the possessor. The naturally occurring examples in (70) reveal that this expectation is realized.

(70) a. Bota 'Ahi', 'No' yänggin malak i saga-n [botasión] hao. vote no no if AGR.go.to the place-L election you 'Vote "No"' when you go to the polls.' (Saipan Tribune 11/4/99)

b. Malak i papa' [nuhung] $y u$ '. AGR.go.to the bottom.L shade I 'I went under the shade.' (Saipan Tribune 2/15/01)

I take this to be satisfying confirmation that the constituents parsed by (48) cannot interrupt a prosodic word and, in this sense, behave like p-phrases. 


\subsection{The Identity of the Leftmost P-Phrase}

Finally, if it is correct that the placement of weak pronouns is characterized in purely prosodic terms, then not only the constituents parsed by (48) but also the domain within which the leftmost such constituent is selected should be prosodic.

I claimed earlier that this larger domain is the i-phrase. The significance of this claim is heightened by the fact that the boundaries of i-phrases are fluid. As mentioned earlier, these prosodic constituents are believed to be "sense units" that are determined semantically-they correspond roughly to clauses or propositions - but whose edges can shift depending on speech rate and other factors (see, e.g., Selkirk 1986:385). The characterization is vague enough that it is hard to imagine what a parsing algorithm for i-phrases in Chamorro would look like (and indeed, I will not attempt to state one). ${ }^{16}$ Nonetheless, if the domain within which "second position" is calculated is truly an i-phrase, some informal expectations arise. If the left edge of this domain can shift, the identity of the leftmost constituent parsed by (48) should likewise shift. Further, if the left edge of the domain is prevented from shifting, the identity of the leftmost constituent parsed by (48) should remain fixed as well.

These predictions, such as they are, are informally supported by two sorts of evidence.

First, the placement of weak pronouns reveals that in Chamorro, the domain within which "second position", is defined usually corresponds to the clause (TP). Material to the left of TP is typically irrelevant. Thus, in (71), the weak pronoun in the relative clause (in brackets) surfaces immediately to the right of the verb of that clause; the higher existential verb taya' 'not exist' is ignored.

\section{(71) Taya' [bumisita $y u^{\prime}$ nigap].}

AGR.not.exist $\mathrm{WH}[\mathrm{NOM}]$.visit me yesterday

'There was no one who visited me yesterday.'

In the constituent questions in $(72 \mathrm{a}-\mathrm{b})$ and the focus construction in $(72 \mathrm{c})$, the weak pronoun surfaces immediately after the verb; the interrogative or focused phrase in C's specifier is ignored.
(72) a. Taimänu [man-hatsa hao guma']? how? AGR.AP-build you house 'How do you build houses?'
b. Hafa [humongngan hao]? what? wH[NOM].surprise you 'What surprised you?'

\footnotetext{
${ }^{16}$ On parsing algorithms for i-phrases, see for example Nespor and Vogel 1986. It could well be that my difficulty in stating a parsing algorithm for i-phrases reflects the fact that i-phrasing is determined from the top down, whereas pphrasing is determined from the bottom up. (Thanks to Bruce Hayes for helpful commentary along these lines.) If so, I must leave the resolution of this implicit conflict for another time.
} 
c. Ni unu [bumíbira gui' tatti]. not one wH[NOM].turn.PROG him back 'No one was returning.' (I Sinku na Mañume'lu 6)

However, exactly when the relevant clause is preceded by material that instantiates a semantic operator - a higher existential verb or a phrase in the specifier of $\mathrm{C}$ - the weak pronoun has the option of occurring farther to the left, outside TP, in a pattern that gives the appearance of clitic climbing. In (73), the weak pronoun surfaces immediately after the higher existential verb (cf. (71)).

(73) kao taya' $\quad y u^{\prime}$ [tumattítiyi]

Q AGR.not.exist me WH[NOM].follow.PROG

'if there was no one following me' (Saipan Tribune 12/22/98)

In (74), the weak pronoun surfaces immediately after material in the specifier of $\mathrm{C}(\mathrm{cf} .(72)) .{ }^{17}$

(74) a. Taimänu hao [man-hatsa guma']? how? you AP-build house 'How do you build houses?'

b. Hafa hao [humongngan]? what? you wH[NOM].surprise 'What surprised you?'

c. Ni unu yu' [umé'e'kunguk]. not one me wH[NOM].listen.PROG

'No one was listening to me.' (Saipan Tribune 7/1/99)

Although this may look like clitic climbing, further examination reveals that here too, the weak pronoun occurs immediately after a constituent parsed by (48). The difference is that in (73)-(74), the relevant constituent is leftmost within a domain that includes the entire sentence. This view is confirmed by examples like (75), in which the weak pronoun surfaces-surprisingly — in the interior of material that instantiates the specifier of $\mathrm{C}$, but — unsurprisingly — after a constituent parsed by (48) that is leftmost within the entire sentence.

(75) Hayi hao na famalao'an [gäi-che'lu]? which? you L women WH[NOM].AGR.have-sibling 'Which girls have you as a sibling?'

\footnotetext{
Compare:

(i) *Ni un taotao [i famagu'un $\mathrm{i}$ chi'lu-mu] [rumipara]. not a person the children.L the sibling-AGR WH[NOM].notice ('No one noticed your sister's children.')
}

${ }^{17}$ As expected by this point, full DPs cannot surface in the position occupied by the weak pronoun in these examples. 
This, I contend, is expected if the larger domain is an i-phrase whose left edge has shifted in (73)-(74) to incorporate the instantiation of semantic operators located outside the clause proper. ${ }^{18}$

Second, the placement of weak pronouns reveals that the larger domain can never be expanded to include a topic DP, although—as shown in (74c) - it can be expanded to include a DP in focus. The point is made by (76), in which the topic si Miguel is coindexed with the (null) possessor of the DP predicate. ${ }^{19}$ The weak pronoun in this sentence can occur to the right of the DP predicate (76a). But it cannot surface immediately after the topic, as (76b) shows.

(76) a. Si Miguel, [patgon-ña $\left.y u^{\prime}\right]$.

Miguel child-AGR I

'As for Miguel, I'm his child.'

b. *Si Miguel yu', [patgon-ña].

Miguel I child-AGR

('As for Miguel, I'm his child')

Why should this be? An explanation suggests itself if we take the domain to be an i-phrase. As shown by Aissen (1992) for Tzotzil and Jakaltek, Frascarelli (2000) for Italian, and others for English, a topic characteristically forms its own separate i-phrase, whereas a focus typically forces adjacent material to dephrase and combine to form an i-phrase with it. (Thanks to Bruce Hayes and Hubert Truckenbrodt for pointing out this generalization.) Assuming that the generalization extends to Chamorro, the reason why (76b) is ungrammatical is that the topic's need to form a separate i-phrase prevents it from being folded into the domain ( $=$ the i-phrase) in which the pronoun is instantiated. Consequently, this second i-phrase and the leftmost p-phrase within it remain fixed as well.

Plausibly, we have here further evidence that the Chamorro domain within which "second position", is calculated is also a prosodic constituent.

\section{Conclusion}

I take it to be firmly established that Chamorro weak pronouns are $2 \mathrm{P}$ clitics whose placement is determined prosodically: they must occur immediately after a p-phrase that is leftmost within an i-phrase. Typologically, this is not an unexpected result. Purely prosodic characterizations have

\footnotetext{
${ }^{18}$ This line of thought leads one to wonder whether the larger domain can ever be expanded leftward to include other types of material - for instance, material instantiating a verb. The example in (i), from an e-mail message, suggests that this is indeed possible.

(i) Bula ti tumungu' hao hayi na taotao. AGR.many not wH[NOM].know you who? L person 'Many do not know exactly who (lit. what person) you are.'

Here, to judge from the placement of the weak pronoun instantiating the embedded subject, the i-phrase corresponding to the embedded clause has evidently expanded leftward to include the verb tumungu' 'know', but not the highest predicate bula '(there are) many'.

${ }^{19}$ This DP is positively identified as the topic by the intonation pattern. Evidence that it does not occupy the specifier of $\mathrm{C}$ is provided by the fact (discussed in section 4.1) that subparts of predicate DPs in Chamorro are inaccessible to wh-movement.
} 
been given of the placement of $2 \mathrm{P}$ clitics in Serbo-Croatian and Ancient Greek-although, as mentioned earlier, these analyses are controversial. Further, the claim that Chamorro weak pronouns must adjoin to p-phrases is consistent with what is known more generally about the crosslinguistic patterning of clitics. Previous research on simple clitics suggests that these forms can choose to adjoin to prosodic constituents at any given level of the prosodic hierarchy, with the possible exception of the utterance (see Inkelas 1990, Zec and Inkelas 1991). In English, Bengali (Lahiri and Fitzpatrick-Cole 1999), and many other languages, simple clitics adjoin to prosodic words; in Hausa, simple clitics adjoin to p-phrases (Inkelas 1990); in Tzotzil and Jakaltek, simple clitics adjoin to i-phrases (Aissen 1992). If $2 \mathrm{P}$ clitics can adjoin to a similar range of prosodic hosts, as seems reasonable, then the requirement that Chamorro weak pronouns must adjoin to p-phrases is not at all surprising.

At the same time, there are perspectives from which this characterization of weak pronouns is instructive. Many syntacticians who encountered these pronouns would, I believe, uncritically assume that their placement could be analyzed in purely syntactic terms. The fact that a prosodic explanation is superior raises the question of how many other patterns presupposed to be syntactic in fact deserve to be accounted for at the syntax-phonology interface, in terms of prosodic structure.

It is now time to address the question of exactly how the placement of weak pronouns comes about. What mechanisms are responsible for causing these forms to surface in the appropriate position in prosodic structure?

A good part of the answer is supplied by Inkelas's (1990) notion of prosodic subcategorization. Suppose we continue to assume, with Inkelas, that clitics are distinguished from independent prosodic words by the fact that their lexical entries include prosodic subcategorization frames. For instance, simple proclitics such as Chamorro si, a morphological case marker for proper names, have a prosodic subcategorization that demands that they adjoin to the left of a prosodic word, as in (77).

(77) $[\mathrm{w}-[\mathrm{w}]]$

Weak pronouns in Chamorro have a prosodic subcategorization that demands that they adjoin to the right of a p-phrase that is leftmost within an i-phrase. This subcategorization, stated earlier in $(51)$, is repeated here.

(51) $\left[{ }_{i}[\mathrm{p}[\mathrm{p}]-]\right.$

More generally, prosodic subcategorization is the mechanism responsible for stating how a clitic is incorporated into prosodic structure.

When and how does prosodic subcategorization come into play? The answer depends partly on one's view of lexical insertion-the operations responsible for introducing lexical items into the derivation. I will consider two views.

In the minimalist approach developed by Chomsky (2001:10), lexical items are, in the simplest case, "once-and-for-all collection[s]" of phonological, semantic, and formal features. (A similar view is expressed in a quite different conceptual framework by Jackendoff (1997:110).) 
Different subsets of these features are accessed by different components of grammar-for instance, formal features are accessed by the syntax and phonological features, by the phonology. But the feature collections themselves are present throughout the portion of the derivation that links the syntax to the phonology. Arrays of lexical items supply the building blocks from which a given syntactic structure is constructed, and these lexical items persist as such when the structure exits, phase by phase, from the syntactic component and is transferred to the phonological component (Chomsky 2001:5, 12-14).

Were we to adopt this view of lexical "insertion," the syntactic structure of (78) might look roughly like (79) as it approaches the phonological component. Each lexical item would consist of a complete bundle of features, including any prosodic subcategorization, although — following convention-none of this is represented in the tree in (79). ${ }^{20}$

(78) Ma'estro-nña gui' si Carmen.

teacher-AGR he Carmen

'He is Carmen's teacher.'

(79)

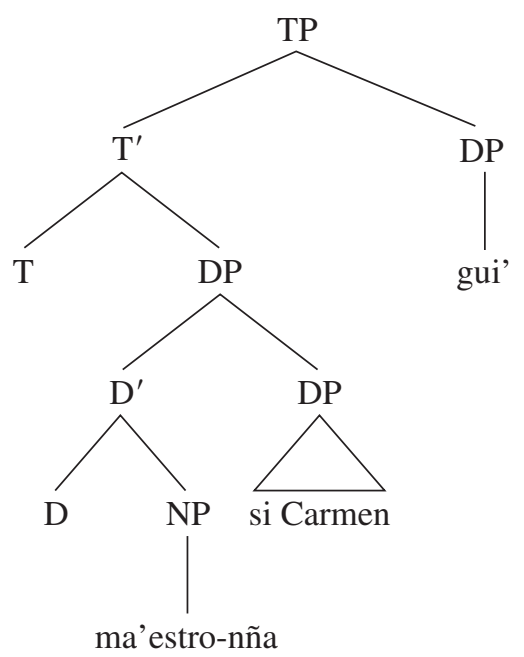

The construction of prosodic structure from this syntactic structure would proceed as follows. First, information supplied by the lexical items in the leaves of the tree in (79) would distinguish

\footnotetext{
${ }^{20}$ Chomsky (2001:12-14) has proposed that syntactic structure is handed over to the phonology in phases. His discussion claims explicitly that syntactic structure exits from the syntax phase by phase, but is silent on the issue of whether each phase reaches the phonology separately or whether the entire syntactic structure arrives at once. Because the i-phrase in Chamorro is sometimes larger than a single strong phase (see (73)), I need to assume that the construction of prosodic structure cannot begin — or, at any rate, cannot proceed past the level of the p-phrase-until the entire syntactic structure can be accessed by prosodic phrase formation. This strikes me as not unreasonable.
} 
the independent prosodic words from the prosodic nonconstituents. This information is represented in (80).

(80)

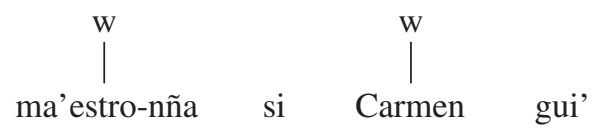

Given this much prosodic structure, the prosodic subcategorization of the proclitic si (77) could be satisfied, so it would adjoin to the following prosodic word, as shown in (81).

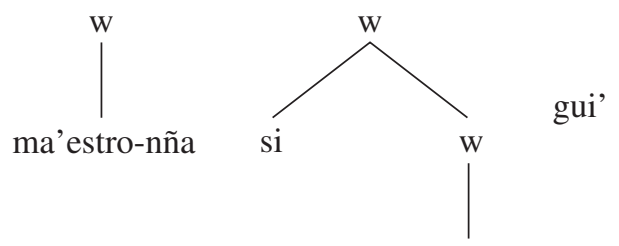

Carmen

Next, the prosodic words in (81) would be grouped into p-phrases by mapping constraint (48), and these p-phrases would then be grouped into i-phrases by another constraint or set of constraints. Consistent with Inkelas's (1990) Strict Parsing (45), these parsing algorithms would ignore the weak pronoun, since it is a prosodic nonconstituent. The result would be the structure shown in (82).

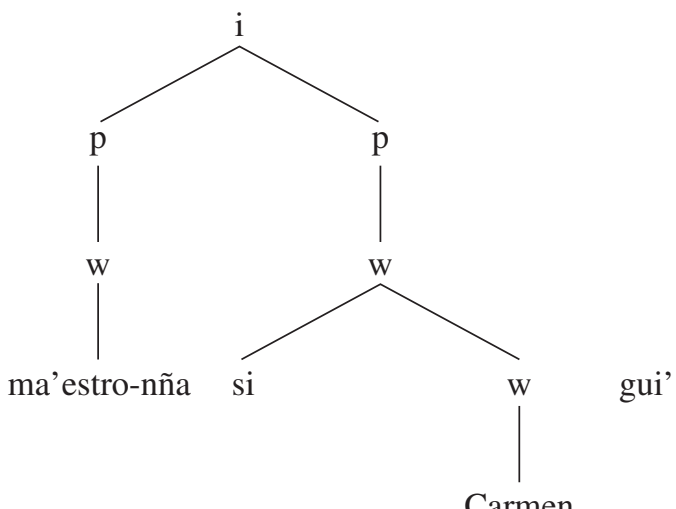

Only at this stage of the building of prosodic structure is it possible for the weak pronoun's prosodic subcategorization to be satisfied. Further, for satisfaction to occur, the weak pronoun cannot remain in place, but must move to adjoin to the right of a p-phrase that is leftmost within an i-phrase. Assuming that the relevant movement respects locality-the pronoun would have to move leftward to the nearest acceptable landing site (i.e., to the designated site within the i-phrase whose left edge occurs most immediately to the left; see (11)) — the result would look like (83). 
(83)

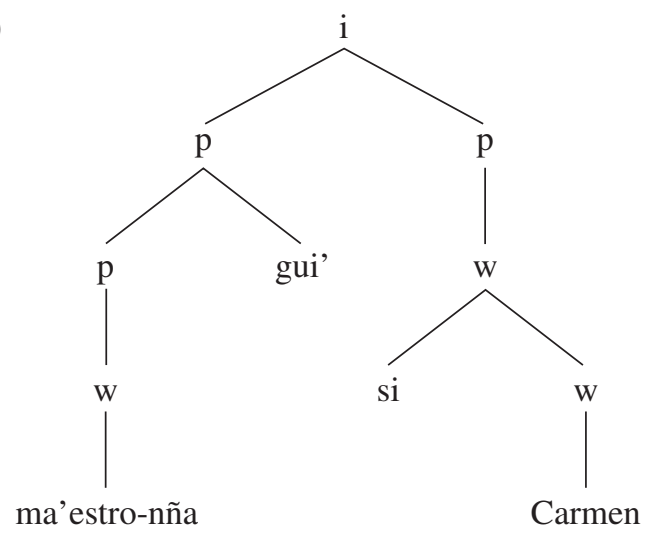

After the i-phrase in (83) is grouped into an utterance, the prosodic structure corresponding to (79) would be complete.

Such an account would achieve the desired result: it would succeed in placing weak pronouns in prosodic structure in the position where they actually occur. Notice that it would crucially appeal to movement in prosodic structure. This PF movement would have a reassuringly familiar look: it would be leftward movement driven by the need to "check" a feature (prosodic subcategorization) and constrained by locality in some sense (i.e., the clitic would move to the nearest appropriate host).

Such an analysis might seem attractive. However, it relies on a theory of lexical items and lexical insertion that cannot explain the results with which this article began: phonological rules do not have direct access to syntactic information, and syntactic operations do not have direct access to phonological information. If lexical items are collections of features present in their entirety throughout the syntax and the phonology, there is no principled reason why access to given features should be prohibited in certain components. The fact that access is blocked must be stipulated. I am claiming, in other words, that the copresent feature specifications posited by the minimalist approach for the individual lexical item serve to undermine the modular architecture of grammar.

The substance of a modular theory can be maintained, I believe, if one adopts the alternative view of lexical insertion espoused by A-morphous Morphology (Anderson 1982, 1992), Distributed Morphology (Marantz 1988, 1989, Halle and Marantz 1993, Embick and Noyer 2001), and Precompiled Phrasal Phonology (Hayes 1990). On this alternative view, the nodes of syntactic structure are morphosyntactic feature bundles that are not phonologically instantiated until after the structure has left the syntax proper. At that point, late lexical insertion occurs, phonologically instantiating each terminal node on the basis of information supplied by an entry in the lexicon.

Suppose we adopt this view and assume further that the operations of late lexical insertion can interact with the building of prosodic structure. This is a possibility anticipated by Hayes (1990:108), who states: 
Both phonological instantiation and phrase formation fall within the 'interface component' that lies between syntax and true phrasal phonology. In principle, some forms of phonological instantiation might follow phrase formation within this component, and thus be able to refer to prosodic domains.

Specifically, suppose that late lexical insertion has access not only to information concerning prosodic words but also to higher levels of prosodic structure as it is being constructed. Suppose further that prosodic subcategorization must be satisfied immediately and locally (in a sense made more precise below), so that a lexical item with a prosodic subcategorization cannot be phonologically instantiated until its subcategorization can be satisfied. Then the mechanism responsible for placing weak pronouns and other Chamorro clitics is very simple: it is just late lexical insertion, whose operations both affect and are affected by the formation of prosodic structure.

To see how the proposal works, consider again the derivation of (78). If lexical insertion is late, the structure produced by the syntax for this example will look like (79) minus the phonological instantiations in the leaves of the tree. The lexical entries for Carmen and the inflected noun ma'estro-nña 'teacher' identify these items as independent prosodic words without a prosodic subcategorization. They can therefore be instantiated right away, producing (84), whose leaves correspond to the initial stage of the construction of prosodic structure.

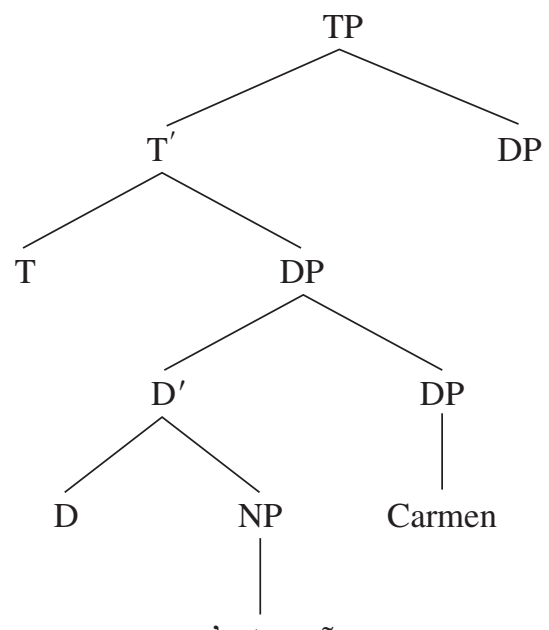

ma'estro-nña

The prosodic information supplied by the phonologically instantiated leaves is represented in (85).

(85)

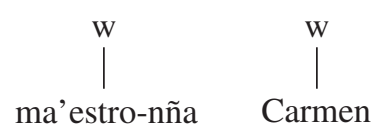

With this much prosodic structure, the prosodic subcategorization of the proclitic $s i$ can be satis- 
fied, so it can be instantiated, adjoined to the prosodic word to its right. The result is shown in (86).

(86)

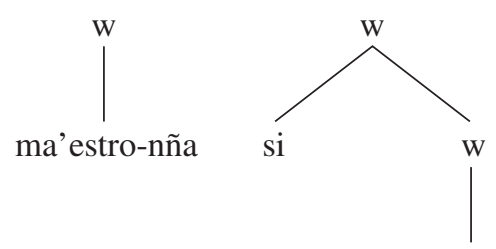

Carmen

The building of prosodic structure then continues as described earlier: as shown in (87), first the prosodic words in (86) are grouped into p-phrases by mapping constraint (48), and then the p-phrases are grouped into i-phrases.

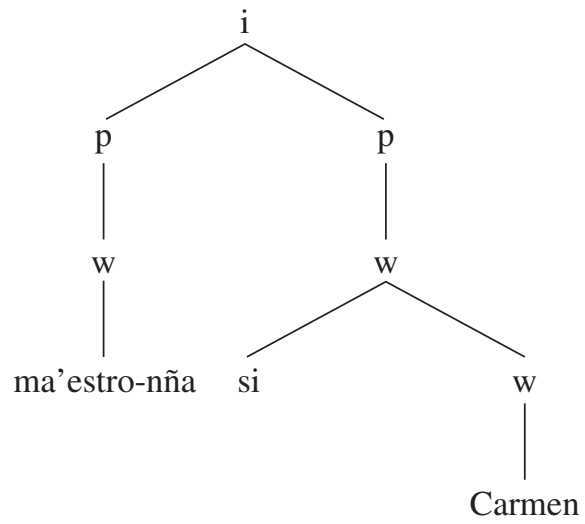

After construction has proceeded this far, the weak pronoun's prosodic subcategorization can be satisfied, so it can be instantiated. Now, it is clear where this form is instantiated in the "interpreted" syntactic structure: just where it occurs in (79). Where is it instantiated in prosodic structure?

The answer is dictated by the claim that prosodic subcategorization must be satisfied immediately and locally. The first requirement is met by adjoining the weak pronoun to a p-phrase that is leftmost within an i-phrase. The second requirement, I claim, is met by instantiating the clitic within the i-phrase corresponding most closely to the clause in which it is instantiated in the "interpreted" structure. (Notice that this is the analogue of the requirement, in the analysis just rejected, that the weak pronoun must move leftward to the nearest acceptable landing site.) The result, once again, is (83).

This account too succeeds in placing weak pronouns in prosodic structure in the position where they actually occur. Two theoretical considerations lead me to prefer it.

First, in this account, the placement of weak pronouns is accomplished by mechanisms that are needed independently: lexical insertion and prosodic subcategorization. The active character 
of prosodic subcategorization in building prosodic substructure has been argued for by Inkelas (1990). The idea that the timing of late lexical insertion can be affected by prosodic subcategorization follows from my claim that the two mechanisms can interact. The systematic correlation between prosodic structure and syntactic structure needed to ensure that prosodic subcategorization is satisfied locally is assumed already; in fact, it lies at the heart of prosodic hierarchy theory. Note that, on this view, no appeal is made to PF movement. ${ }^{21}$

Second, in this account, the mutual interaction of syntax and phonology is confined to the postsyntactic operations that translate syntax into prosodic structure: late lexical insertion and prosodic phrase formation. The fact that the picture that emerges is consistent with a fundamentally modular architecture of grammar I take to be a welcome result.

\section{Appendix: The Placement of Weak Pronouns in Coordinate Structures}

Coordinate structures offer an important testing ground for the analysis of weak pronouns developed in the text, as Sharon Inkelas has pointed out to me. Regardless of how coordinate structures are dealt with in the syntax, they must be linearized in the phonology, with the result that conjoined XPs should be mapped onto multiple p-phrases whereas conjoined heads should not be (see, e.g., Clements 1978 on Ewe and Chen 1987 on Xiamen). This leads to some specific predictions concerning the placement of weak pronouns.

1. A weak pronoun should never interrupt a sequence of conjoined predicate heads, all of which are independent prosodic words. The reason is that these heads should all be mapped into the same p-phrase by mapping constraint (48).

2. A weak pronoun should be able to interrupt a sequence of conjoined predicate XPs. The reason is that unless prosodic dependence intervenes, each conjunct XP should be mapped onto a separate p-phrase by mapping constraint (48).

3. Assuming that the i-phrase corresponds to the clause, a weak pronoun should surface within the leftmost conjunct XP in a sequence of conjoined predicate XPs, if it surfaces within any conjunct XP at all. This is because the leftmost p-phrase within the i-phrase should correspond to (some subpart of) the leftmost conjunct XP.

4. Predictions 1-3 should hold whether the weak pronoun instantiates a subject or a direct object.

The investigation of these predictions is complicated by two factors. First, Chamorro is a null argument language. This means, among other things, that many examples that appear to be single clauses containing conjoined predicate XPs can also be analyzed as conjoined clauses. The ambiguity could well have an impact on prosodic constituency at the level of the i-phrase, and

\footnotetext{
${ }^{21}$ It is important that there is no PF movement hidden in this account. One defining characteristic of movement is that the structure in which the moved item occurs and the structure in which it occurs unmoved are constructed from the same primitives. But in the derivation just provided, the weak pronoun enters prosodic structure in second position. It cannot have moved there, because the only structures in which it is instantiated in a different position are "interpreted" syntactic structures.
} 
therefore on the placement of weak pronouns (although it is difficult to tell, given the unclarity over how material is parsed into i-phrases). Second, the crucial example types mentioned in predictions 1-3 are not frequent in textual material. I have already commented on the difficulty of investigating the placement of weak pronouns via elicitation (see footnote 3 ).

Nonetheless, on the basis of consultation with four Chamorro speakers, I can report the following.

It appears that in clauses containing conjoined verbs, a weak pronoun that instantiates a direct object shared by these verbs cannot occur immediately after the leftmost conjunct V. (In the examples below, each conjunct is bracketed separately.)

(88) *Kao [ha-guaiya] hit yan [ha-rispeta] ädyu na patgun?

Q AGR-love us and AGR-respect that L child

('Does that child love and respect us?')

Such a pronoun can, however, occur after the entire coordinate structure.

(89) Kao [ha-guaiya] yan [ha-rispeta] hit ädyu na patgun?

Q AGR-love and AGR-respect us that $\mathrm{L}$ child

'Does that child love and respect us?'

If one takes the naturally occurring example in (90) to involve conjoined adjectives, it illustrates a similar pattern with a weak pronoun that instantiates the subject.

(90) Inipus [man-malisiosu] yan [imbidiosu] hit na taotagui.

exceedingly AGR-malicious and envious we $\mathrm{L}$ people

'We are a too malicious and envious people.' (Saipan Tribune 4/7/00)

All this is consistent with prediction 1 .

It appears that in clauses containing conjoined predicate DPs, a weak pronoun that instantiates the subject can occur immediately after the leftmost conjunct DP. In (91), notice that both possessed nouns are inflected via the linker and are therefore proclitic.

(91) [Infitmera-n Rosa] yu’ yan [doktu-n Julia].

nurse-L Rosa I and doctor-L Julia

'I'm Rosa's nurse and Julia's doctor.'

This is consistent with prediction 2 .

Matters become more complicated when one turns to clauses containing conjoined VPs. In such clauses, some speakers find that a weak pronoun subject can surface only within the left conjunct VP, whereas other speakers find that a weak pronoun subject can surface only within the right conjunct VP. The first pattern is consistent with prediction 3; the second pattern, illustrated here, is not.

(92) *Kao [kumómotgan hao] yan [binindisi as Pali' Dueñas]?

Q AGR.take.communion you and AGR.PAss.bless by Father Dueñas

('Did you take communion and get blessed by Father Dueñas?') 
(93) Kao [kumómotgan] yan [binindisi hao as Pali' Dueñas]?

Q AGR.take.communion and AGR.PASs.bless you by Father Dueñas

'Did you take communion and get blessed by Father Dueñas?'

While it is unclear (to me) how to handle this variability, it should be noted that both patterns differentiate weak pronoun subjects from the corresponding full DPs. Subjects that are full DPs can routinely surface within any conjunct VP, as (94)-(95) are intended to suggest (see Chung 1998:133-139).

(94) Kao [kumómotgan

si Dolores] yan [binindisi as Pali' Dueñas]?

Q AGR.take.communion Dolores and AGR.PASs.bless by Father Dueñas

'Did Dolores take communion and get blessed by Father Dueñas?'
Kao [kumómotgan]
yan [binindisi
si Dolores as Pali'
Dueñas]?
Q AGR.take.communion and AGR.PAss.bless Dolores by Father Dueñas
'Did Dolores take communion and get blessed by Father Dueñas?'

The picture becomes even less rosy when one considers the placement of weak pronouns that instantiate direct objects of conjoined VPs. Continuing to assume that the i-phrase corresponds to the clause, the expectation here, as before, is that such pronouns should surface immediately to the right of the leftmost p-phrase within the i-phrase. A weak pronoun that instantiates the direct object of a right conjunct VP should therefore surface within the leftmost conjunct VP. Unsurprisingly, this does not happen. Instead, the pronoun surfaces immediately after the verb on which it is semantically and syntactically dependent. Compare (88)-(89) with (96).

(96) Kao [ha-guaiya hit] an [ha-rispeta hit] ädyu na patgun?

Q AGR-love us and AGR-respect us that $\mathrm{L}$ child

'Does that child love us and respect us?'

This result is inconsistent with predictions 3-4.

I have no account to offer of (92) or (96), beyond observing that both of these problematic cases involve conjoined VPs. More detailed investigation must be left for another time.

\section{References}

Abney, Stephen P. 1987. The English noun phrase in its sentential aspect. Doctoral dissertation, MIT, Cambridge, Mass.

Aissen, Judith. 1992. Topic and focus in Mayan. Language 68:43-80.

Aldridge, Edith. 2002. Nominalization and wh-movement in Seediq and Tagalog. Language and Linguistics 3:393-427.

Anderson, Stephen R. 1982. Where's morphology? Linguistic Inquiry 13:571-612.

Anderson, Stephen R. 1992. A-morphous morphology. Cambridge: Cambridge University Press.

Anderson, Stephen R. 1993. Wackernagel's revenge: Clitics, morphology, and the syntax of second position. Language 69:68-98.

Anderson, Stephen R. 2000. Towards an optimal account of second position phenomena. In Optimality Theory: Phonology, syntax, and acquisition, ed. by Joost Dekkers, Frank van der Leeuw, and Jeroen van de Weijer, 302-333. Oxford: Oxford University Press. 
Black, H. Andrew. 1992. South American verb second phenomena: Evidence from Shipibo. In Syntax at Santa Cruz, vol. 1, ed. by H. Andrew Black and James McCloskey, 35-63. Santa Cruz: University of California, Santa Cruz, Syntax Research Center.

Bošković, Željko. 2001. On the nature of the syntax-phonology interface: Cliticization and related phenomena. Amsterdam: Elsevier.

Chen, Matthew Y. 1987. The syntax of Xiamen tone sandhi. Phonology Yearbook 4:109-149.

Chomsky, Noam. 1986. Barriers. Cambridge, Mass.: MIT Press.

Chomsky, Noam. 2001. Derivation by phase. In Ken Hale: A life in language, ed. by Michael Kenstowicz, 1-52. Cambridge, Mass.: MIT Press.

Chung, Sandra. 1998. The design of agreement: Evidence from Chamorro. Chicago: University of Chicago Press.

Chung, Sandra. To appear. VOS clauses. In The syntax companion (Syncom), ed. by Martin Everaert and Henk van Riemsdijk. Oxford: Blackwell.

Clements, George N. 1978. Tone and syntax in Ewe. In Elements of tone, stress, and intonation, ed. by Donna Jo Napoli, 21-99. Washington, D.C.: Georgetown University Press.

Condoravdi, Cleo, and Paul Kiparsky. 2002. Clitics and clause structure. Ms., Stanford University, Stanford, Calif.

Cooreman, Ann. 1982. Chamorro texts. Ms., University of Oregon, Eugene.

Cooreman, Ann. 1983. Chamorro texts. Ms., Saipan, CNMI.

Davies, William D., and Stanley Dubinsky. 2001. Remarks on grammatical functions in transformational syntax. In Objects and other subjects: Grammatical functions, functional categories and configurationality, ed. by William D. Davies and Stanley Dubinsky, 1-19. Dordrecht: Kluwer.

Diesing, Molly. 1992. Indefinites. Cambridge, Mass.: MIT Press.

Embick, David, and Rolf Noyer. 2001. Movement operations after syntax. Linguistic Inquiry 32:555-595.

Frascarelli, Mara. 2000. The syntax-phonology interface in focus and topic constructions in Italian. Dordrecht: Kluwer.

Grimshaw, Jane. 2000. Extended projection and locality. In Lexical specification and insertion, ed. by Peter Coopmans, Martin Everaert, and Jane Grimshaw, 115-133. Amsterdam: John Benjamins.

Hale, Ken, and Elisabeth Selkirk. 1987. Government and tonal phrasing in Papago. Phonology Yearbook 4: 151-183.

Halle, Morris, and Alec Marantz. 1993. Distributed Morphology and the pieces of inflection. In The view from Building 20: Essays in linguistics in honor of Sylvain Bromberger, ed. by Kenneth Hale and Samuel Jay Keyser, 111-176. Cambridge, Mass.: MIT Press.

Halpern, Aaron L. 1995. On the placement amd morphology of clitics. Stanford, Calif.: CSLI Publications.

Haverkort, Marco. 1993. Clitics and parameterization: Case studies in the interaction of head movement phenomena. Eurotyp Program in Language Typology, European Science Foundation.

Hayes, Bruce. 1989. The prosodic hierarchy in meter. In Phonetics and phonology 1: Rhythm and meter, ed. by Paul Kiparsky and Gilbert Youmans, 201-260. San Diego, Calif.: Academic Press.

Hayes, Bruce. 1990. Precompiled phrasal phonology. In The phonology-syntax connection, ed. by Sharon Inkelas and Draga Zec, 85-108. Chicago: University of Chicago Press.

Hock, Hans Heinrich. 1996. Who's on first? Toward a prosodic account of P2 clitics. In Approaching second: Second position clitics and related phenomena, ed. by Aaron L. Halpern and Arnold M. Zwicky, 199-270. Stanford, Calif.: CSLI Publications.

Huddleston, Rodney, and Geoffrey K. Pullum, eds. 2001. The Cambridge grammar of the English language. Cambridge: Cambridge University Press.

Hyman, Larry M., Francis Katamba, and Livingstone Walusimbi. 1987. Luganda and the strict layer hypothesis. Phonology Yearbook 4:87-108.

Inkelas, Sharon. 1990. Prosodic constituency in the lexicon. New York: Garland. 
Jackendoff, Ray. 1997. The architecture of the language faculty. Cambridge, Mass.: MIT Press.

Kaisse, Ellen M. 1985. Connected speech: The interaction of syntax and phonology. Orlando, Fla.: Academic Press.

Kayne, Richard S. 1994. The antisymmetry of syntax. Cambridge, Mass.: MIT Press.

Klavans, Judith. 1985. The independence of syntax and phonology in cliticization. Language 61:95-120.

Lahiri, Aditi, and Jennifer Fitzpatrick-Cole. 1999. Emphatic clitics and focus intonation in Bengali. In Phrasal phonology, ed. by René Kager and Wim Zonneveld. Nijmegen: Nijmegen University Press.

Lee, Felicia. 2000. VP remnant movement and VSO in Quiavini Zapotec. In The syntax of verb initial languages, ed. by Andrew Carnie and Eithne Guilfoyle, 143-162. Oxford: Oxford University Press.

Legendre, Géraldine. 1996. Clitics, verb (non-)movement, and optimality in Bulgarian. Technical report JHU-CogSci-96-5. Baltimore, Md.: Johns Hopkins University, Department of Cognitive Science.

Marantz, Alec. 1988. Clitics, morphological merger, and the mapping to phonological structure. In Theoretical morphology: Approaches in modern linguistics, ed. by Michael Hammond and Michael Noonan, 253-270. San Diego, Calif.: Academic Press.

Marantz, Alec. 1989. Clitics and phrase structure. In Alternative conceptions of phrase structure, ed. by Mark R. Baltin and Anthony S. Kroch, 99-116. Chicago: University of Chicago Press.

Massam, Diane. 2000. VSO and VOS: Aspects of Niuean word order. In The syntax of verb initial languages, ed. by Andrew Carnie and Eithne Guilfoyle, 97-116. Oxford: Oxford University Press.

Massam, Diane. 2001. Pseudo noun incorporation in Niuean. Natural Language \& Linguistic Theory 19: 153-197.

Nespor, Marina, and Irene Vogel. 1982. Prosodic domains of external sandhi rules. In The structure of phonological representations, part 1, ed. by Harry van der Hulst and Norval Smith, 225-255. Dordrecht: Foris.

Nespor, Marina, and Irene Vogel. 1986. Prosodic phonology. Dordrecht: Foris.

Pearson, Matthew. 1998. Predicate raising and "VOS" order in Malagasy. In The structure of Malagasy: Volume 2, ed. by Ileana Paul, 94-110. Los Angeles: UCLA, Department of Linguistics.

Progovac, Ljiljana. 1996. Clitics in Serbian/Croatian: Comp as the second position. In Approaching second: Second position clitics and related phenomena, ed. by Aaron L. Halpern and Arnold M. Zwicky, 411-428. Stanford, Calif.: CSLI Publications.

Pullum, Geoffrey K., and Arnold M. Zwicky. 1988. The syntax-phonology interface. In Linguistics: The Cambridge survey. Vol. 1, Linguistic theory: Foundations, ed. by Frederick J. Newmeyer, 255-280. Cambridge: Cambridge University Press.

Rackowski, Andrea, and Lisa Travis. 2000. V-initial languages: X or XP movement and adverbial placement. In The syntax of verb initial languages, ed. by Andrew Carnie and Eithne Guilfoyle, 117-141. Oxford: Oxford University Press.

Radanović-Kocić, Vesna. 1988. The grammar of Serbo-Croatian clitics: A synchronic and diachronic perspective. Doctoral dissertation, University of Illinois at Urbana-Champaign.

Radanović-Kocić, Vesna. 1996. The placement of Serbo-Croatian clitics: A prosodic approach. In Approaching second: Second position clitics and related phenomena, ed. by Aaron L. Halpern and Arnold M. Zwicky, 429-445. Stanford, Calif.: CSLI Publications.

Rivero, María Luisa. 1994. Clause structure and V-movement in the languages of the Balkans. Natural Language \& Linguistic Theory 12:63-120.

Sadock, Jerrold M. 1991. Autolexical syntax: A theory of parallel grammatical representations. Chicago: University of Chicago Press.

Selkirk, Elisabeth. 1980. Prosodic domains in phonology: Sanskrit revisited. In Juncture, ed. by Mark Aronoff and Mary-Louise Kean, 107-129. Saratoga, Calif.: Anma Libri.

Selkirk, Elisabeth. 1986. On derived domains in sentence phonology. Phonology Yearbook 3:371-405. 
Selkirk, Elisabeth, and Koichi Tateishi. 1991. Syntax and downstep in Japanese. In Interdisciplinary approaches to language: Essays in honor of S.-Y. Kuroda, ed. by Carol Georgopoulos and Roberta Ishihara, 519-543. Dordrecht: Kluwer.

Soh, Hooi Ling. 2001. The syntax and semantics of phonological phrasing in Shanghai and Hokkien. Journal of East Asian Linguistics 10:37-80.

Taylor, Ann. 1996. A prosodic account of clitic position in Ancient Greek. In Approaching second: Second position clitics and related phenomena, ed. by Aaron L. Halpern and Arnold M. Zwicky, 477-503. Stanford, Calif.: CSLI Publications.

Truckenbrodt, Hubert. 1995. Phonological phrases: Their relation to syntax, focus, and prominence. Doctoral dissertation, MIT, Cambridge, Mass.

Truckenbrodt, Hubert. 1999. On the relation between syntactic phrases and phonological phrases. Linguistic Inquiry 30:219-255.

Zec, Draga, and Sharon Inkelas. 1990. Prosodically constrained syntax. In The phonology-syntax connection, ed. by Sharon Inkelas and Draga Zec, 365-378. Chicago: University of Chicago Press.

Zec, Draga, and Sharon Inkelas. 1991. The place of clitics in the prosodic hierarchy. In The proceedings of the Tenth West Coast Conference on Formal Linguistics, ed. by Dawn Bates, 505-519. Stanford, Calif.: CSLI Publications.

Zwicky, Arnold M. 1977. On clitics. Bloomington: Indiana University Linguistics Club.

Zwicky, Arnold M., and Geoffrey K. Pullum. 1983. Cliticization vs. inflection: English n't. Language 59: 502-513.

Cowell Academic Services

University of California, Santa Cruz.

Santa Cruz, California 95064

schung@ucsc.edu 